\title{
Article
}

\section{A novel oligomer containing DOPO and ferrocene groups: Synthesis, characterization, and its application in fire retardant epoxy resin}

Wen, Yi, Cheng, Zhou, Li, Wenxiong, Liao, Duijun, Huang, Xiaoping, Pan, Ning, Wang, Deyi and Hull, T Richard

Available at http://clok.uclan.ac.uk/24168/

Wen, Yi, Cheng, Zhou, Li, Wenxiong, Liao, Duijun, Huang, Xiaoping, Pan, Ning, Wang, Deyi and Hull, T Richard ORCID: 0000-0002-7970-4208 (2018) A novel oligomer containing DOPO and ferrocene groups: Synthesis, characterization, and its application in fire retardant epoxy resin. Polymer Degradation and Stability, 156 . pp. 111-124. ISSN 0141-3910

It is advisable to refer to the publisher's version if you intend to cite from the work. http://dx.doi.org/10.1016/j.polymdegradstab.2018.08.010

For more information about UCLan's research in this area go to http://www.uclan.ac.uk/researchgroups/ and search for < name of research Group>.

For information about Research generally at UCLan please go to http://www.uclan.ac.uk/research/

All outputs in CLoK are protected by Intellectual Property Rights law, including Copyright law. Copyright, IPR and Moral Rights for the works on this site are retained by the individual authors and/or other copyright owners. Terms and conditions for use of this material are defined in the policies page. 


\section{A novel oligomer containing DOPO and ferrocene groups:}

\section{synthesis, characterization, and its application in fire retardant}

\section{epoxy resin}

Yi Wen a , Zhou Cheng ${ }^{a}$, Wenxiong $\mathrm{Li}^{\mathrm{a}}$, Zhi Li ${ }^{\mathrm{c}}$, Duijun Liao ${ }^{a}$, Xiaoping Hu ${ }^{a^{*}}$, Ning Pan ${ }^{b}$, Deyi Wangc, T. Richard Hull $\mathrm{d}^{*}$

${ }^{a}$ State Key Laboratory for Environment-friendly Energy Materials, School of Materials Science and Engineering, Southwest University of Science and Technology, Mianyang 621010, P. R. China

${ }^{b}$ Fundamental Science on Nuclear Wastes and Environmental Safety Laboratory, Southwest University of Science and Technology, Mianyang 621010, P. R. China

CIMDEA Materials Institute, C/Eric Kandel, 2, 28906 Getafe, Madrid, Spain

${ }^{d}$ Centre for Fire and Hazards Science, University of Central Lancashire, Preston PR1 2HE, UK

*Corresponding Author. E-mail address: huxiaoping@swust.edu.cn (Xiaoping Hu), trhull@uclan.ac.uk (T. Richard Hull)

\section{Abstract}

A novel oligomer (PFDCHQ) based on 9,10-dihydro-9-oxa-10-phosphaphenanthrene -10-oxide (DOPO) and ferrocene groups was synthesized successfully, aiming at improving the flame retardant efficiency of diglycidyl ether of bisphenol $A$ epoxy resin (DGEBA). FTIR, ${ }^{1} \mathrm{H}$ NMR and ${ }^{31} \mathrm{P}$ NMR were used to confirm the chemical structure of PFDCHQ. The high char yields of $60.3 \mathrm{wt} \%$ and $20.1 \mathrm{wt} \%$ were obtained for PFDCHQ from TGA results in nitrogen and air atmosphere, respectively. The thermal degradation mechanism of PFDCHQ was investigated by TG-FTIR and Py-GC/MS. The limiting oxygen index (LOI) of EP- 5 with $5 \mathrm{wt} \%$ loading of PFDCHQ increased to $32.0 \%$ and the UL-94 V-0 rating was achieved, showing a notable blowing-out effect . In contrast to EP-0, the peak of the heat release rate (pHRR) and total heat release (THR) of EP- 5 decreased by $18.0 \%$ and $10.3 \%$. The flame retardant mechanism of PFDCHQ in epoxy resin was studied by TG-FTIR, SEM and Raman. SEM and Raman results indicated the formation of coherent and dense char residue with high degree of graphitization due to the incorporation of PFDCHO. In UL-94, the blowing-out effect dominantly accounted for the enhanced flame retardancy in combination with optimized char structure. Furthermore, the addition of PFDCHQ improved the Young's modulus compared to EP-0.

Keywords: DOPO-HQ; Ferrocene; Synthesis; Epoxy resin; Flame retardant mechanism

\section{Introduction}

Epoxy resin (EP) is widely applied in many areas such as coating, adhesive, laminating, electronic/electrical insulation, and composite application [1-3], due to its excellent mechanical properties, chemical stability, bonding behavior and abundant product forms [4-6]. However, the high flammability is a general shortcoming of EP and limits its applications. Therefore, it has attracted more and more attention to endow EP with required flame-retardance. 
As an important halogen-free flame retardant, phosphorus flame retardants (PFRs) $[7,8]$ have attracted extensive attention [9-11] for their high efficiency. Most of the PFRs not only play flame retardant effects through a protective char layer caused by the catalyzation of phosphoric acid $[12,13]$, but also play flame retardant role in the gas phase through the radical trapping by PO and $\mathrm{PO}_{2}$ fragments [14, 15]. In recent years, 9,10-dihydro-9-oxa-10-phosphaphenanthrene-10oxide (DOPO) and its derivatives, as a novel kind of PFRs, have received considerable attention attributed to their high reactivity [16]. When DOPO-based PFRs are applied in epoxy resin, it is often used in conjunction with nitrogen/silicon elements as small molecular PFRs [17-19]. However, the non-polymeric PFRs display many drawbacks such as poor compatibility with polymer matrix and easily leaching. Comparatively, DOPO-containing polymeric flame retardants not only have higher phosphorus content and richer aromatic group structures, but also can overcome these shortcomings of small molecular PFRs [20, 21].

The 10-(2,5-Dihydroxyphenyl)-10H-9-oxa-10-phospha-phenantbrene-10-oxide (DOPO-HQ) is one of the most important derivatives of DOPO. The two hydroxyl groups in DOPO-HQ molecule can react with other active function groups to form polymeric phosphorus-containing flame retardants, which have good compatibility with epoxy resin and are not easily migrated during the processing or using according to the published literature [22, 23]. Wang et al. synthesized a polymeric PFR based on 10-(2, 5-dihydroxyl-phenyl)-9, 10-dihydro-9-oxa-10-

phosphaphenanthrene-10-oxide (DOPO-BQ) and pentaerythritol diphosphonate dichloride (SPDPC), a V-0 rating in the UL-94 test was obtained with PFR content of $10 \mathrm{wt} \%$ in epoxy resin

[24]. Carja et al. reported a new phosphorus flame retardant by solution polycondensation of 1,4phenylenebis phenylenebis ((6-oxido-6H-dibenz[c,e][1,2]oxaphosphorinyl) carbinol) with phenylphosphonic dichloride, and a UL-94 V-0 rating material was obtained when $14.8 \mathrm{wt} \%$ PFR were added into the epoxy matrix [23]. In addition, Tian et al. synthesized a novel organophosphorus named as poly(4,4-dihydroxy-1-methyl-ethyl diphenol-o-bicyclic pentaerythritol phosphatephosphate) (PCPBO) and achieved good flame retardant epoxy resin composites with the formation of an intumescent char layer [25]. However, the high loadings was needed to reach the $\mathrm{V}-0$ level due to the poor catalytic effect of phosphoric acid and the low flame-retardant efficiency when these reported polymeric PFRs were used in epoxy materials. Therefore, it is a preferable idea to introduce a functional group with high-effective catalyzing function onto PFR molecules for more char formation. It is already known that transition metals including $\mathrm{Fe}$, $\mathrm{Co}$ and $\mathrm{Ni}$ can cause catalytic char-formation of polymer [26-28]. So, it is a promising way to combining iron-containing unit with phosphorus-containing unit.

Ferrocene has received considerable attention due to its effective smoke suppression and catalyzing crosslinking performance [29, 30]. The previous reports revealed that some polymers containing ferrocene and phosphorus had high char yield and thermal stability [31, 32]. Kishore et al. synthesized a series of polyphosphate esters containing ferrocene. Theses polyesterphosphate esters ( $\mathrm{VI}, \mathrm{VII}, \mathrm{VIII}, \mathrm{IX}$ and X) provided high char residues of $28 \%, 38 \%, 27 \%, 23 \%$ and $32 \%$ at $700{ }^{\circ} \mathrm{C}$ [33]. Mehdipour-Ataei reported a battery of ferrocene-based polyamides and had high char yield from $43 \%$ to $72 \%$ at $600{ }^{\circ} \mathrm{C}$ [34]. Besides, Liao synthesized a novel ferrocene-based copolymer with $62 \%$ char residue at $700^{\circ} \mathrm{C}$ under nitrogen. When applied it in epoxy resin, a UL- 
$94 \mathrm{~V}-1$ rating and LOI value of $29.2 \%$ are obtained, which is attributed to the excellent catalytic charring capacity of ferrocene-based copolymer [35].

Combined the merits of DOPO and ferrocene groups, a novel oligomeric flame retardant poly 10(2,5-dihydroxyphenyl)-9,10-dihydro-9-oxa-10-phospha Phenanthrene-10-oxide-1,1'-ferrocene dimethyl ester (PFDCHQ) containing DOPO-HQ and ferrocene was synthesized and incorporated into diglycidyl ether of bisphenol A epoxy resin (DGEBA) to improve its fire retardancy. The chemical structure of PFDCHQ was characterized by FTIR, ${ }^{1} \mathrm{H}$ NMR and ${ }^{31} \mathrm{P} N M R$. The fire retardancy, flame retardant mechanism and mechanical properties of EP/PFDCHQ composites were comprehensively studied. The results show that PFDCHQ is a kind of high-effective flame retardant for epoxy resin material.

\section{Experimental}

\subsection{Materials}

Ferrocene (98\%), oxalyl dichloride (98.0\%) and methylene dichloride $\left(\mathrm{CH}_{2} \mathrm{Cl}_{2}, \quad 99.5 \%\right)$ were purchased from Sinpharm Chemical Reagent Co. Ltd. (China). DOPO-HQ (Huizhou sunstar technology Co. Ltd., China) was used without further purification. Sodium hypochlorite solution (active chlorine is $10 \%$ ) was provided from Shanghai Aladdin Biochemical Technology Co. Ltd. (China). Petroleum ether was provided by Tianjin Zhiyuan Chemical Reagent Co. Ltd. (China). Epoxy resin (DGEBA, commercial name: E-44, with an epoxy value of 0.41-0.48) was supplied by Nantong Xingchen Synthetic Material Co. Ltd. (Jiangsu China). The curing agent mPhenylenediamine (m-PDA) was purchased from Tianjin Guangfu Co. Ltd. (China).

\subsection{Preparation of $P F D C H Q$}

\subsubsection{Synthesis of 1,1'-diacetylferrocene (DAF)}

In a $500 \mathrm{ml}$ three-necked flask with a magnetic stirrer, flux condenser and nitrogen inlet, $\mathrm{AlCl}_{3}$ (46.7 g, $0.35 \mathrm{~mol}$ ) and $125 \mathrm{ml} \mathrm{CH}_{2} \mathrm{Cl}_{2}$ were introduced into it. The mixture was stirred at room temperature for $5 \mathrm{~min}$. Then, the $\mathrm{AlCl}_{3}$ was dissolved after adding $107 \mathrm{ml}$ acetyl chloride dropwise through dropping funnel. Next, ferrocene $(18.6 \mathrm{~g}, 0.1 \mathrm{~mol}$, dissolved in $100 \mathrm{ml}$ absolute $\mathrm{CH}_{2} \mathrm{Cl}_{2}$ ) was added dropwise. The reaction mixture was stirred at room temperature for $2 \mathrm{~h}$ and the dark purple solution was produced. Afterwards, the solution was slowly poured into lots of ice. The organic phase and water phase were separated with a separating funnel. After that, the organic phase was washed with water and extracted, repeatedly three times, then the $\mathrm{CH}_{2} \mathrm{Cl}_{2}$ was rotary evaporated. The crude product was purified by petroleum ether until the washing liquid was colorless. Finally, recrystallization from water gave $20.25 \mathrm{~g}$ (yield: $75 \%$ ) of red acicular crystal, which was named as DAF. FT-IR ( $\left.\mathrm{KBr}, \mathrm{cm}^{-1}\right)$ v: $3435\left(\mathrm{H}_{2} \mathrm{O}\right)$; $3094(\mathrm{Cp}-\mathrm{H})$; $1660(-\mathrm{C}=\mathrm{O}) ; 2980,1456$ and $1375\left(-\mathrm{CH}_{3}\right) ; 1297,1150,842,542$ and 502 (Cp ring). ${ }^{1} \mathrm{H}$ NMR (600 MHz, $\left.\mathrm{CDCl}_{3}, \delta, \mathrm{ppm}\right): 4.51$ $(4 \mathrm{H}, \mathrm{s}, \mathrm{Cp}), 4.77(4 \mathrm{H}, \mathrm{s}, \mathrm{Cp}), 2.35\left(6 \mathrm{H}, \mathrm{s},-\mathrm{CH}_{3}\right)$. The corresponding spectra are shown in Fig. $\mathrm{S} 1$.

\subsubsection{Synthesis of $1,1^{\prime}$-Ferrocenedicarboxylic acid (FDC)}

DAF (13.3 g) was added to $350 \mathrm{ml}$ of $10 \%$ sodium hypochlorite solution at $65^{\circ} \mathrm{C}$ and rapid stirred in the dark. A further $200 \mathrm{ml}$ of sodium hypochlorite solution was added after $2 \mathrm{~h}$, and kept rapidly stirring for $6 \mathrm{~h}$ at $65^{\circ} \mathrm{C}$. Then the reaction solution was filtered hot and acidified to $\mathrm{pH} 1-2$ 
with concentrated hydrochloric acid, forming a copious orange precipitation. The crude product was filtered, next dissolved in sodium hydroxide solution, and subsequently, reacidified with concentrated hydrochloric acid and precipitated to obtain pure orange 1,1'-ferrocenedicarboxylic acid, which was named as FDC (10.8 g, yield: $81 \%)$. FTIR $\left(\mathrm{KBr}, \mathrm{cm}^{-1}\right)$ v: $3435\left(\mathrm{H}_{2} \mathrm{O}\right), 3200-2500$ (association of -OH), 1688, 1302 (COO) [36]; 1492, 1169 and 841 (Cp ring); 1405, 919 (O-H); ${ }^{1} \mathrm{H}$ NMR $\left(600 \mathrm{MHz}, \mathrm{CH}_{3} \mathrm{COOH}-\mathrm{d}_{4}, \delta, \mathrm{ppm}\right): 4.57(4 \mathrm{H}, \mathrm{s}, \mathrm{Cp}), 4.93(4 \mathrm{H}, \mathrm{s}, \mathrm{Cp}), 11.59(-\mathrm{COOH})$. The FTIR and ${ }^{1} \mathrm{H}$ NMR spectra are shown in Fig. S2.

\subsubsection{Synthesis of PFDCHQ}

1,1'-Ferrocenedicarbonly chloride was prepared according to previous work [37]. In a $500 \mathrm{ml}$ three-necked flask equipped with a magnetic stirrer and condenser, $\mathrm{FDC}(13.0 \mathrm{~g}), \mathrm{CH}_{2} \mathrm{Cl}_{2}(200 \mathrm{ml})$, oxalyl chloride $(20 \mathrm{ml})$ and 10 drops of pyridine were added and the reaction mixture was stirred at room temperature for $12 \mathrm{~h}$. Subsequently, the mixture was heated to reflux temperature for 6 $\mathrm{h}$. Then, the solvent and unreaction oxalyl chloride were removed by rotary evaporated under reduced pressure to obtain crude product. Finally, the crud product was extracted repeatedly with hot petroleum until the petroleum is colorless and the crimson product was obtained, which is named as $1,1^{\prime}$-Ferrocenedicarbonly chloride.

DOPO-HQ $(0.03 \mathrm{~mol})$ was dispersed in $150 \mathrm{ml}$ absolute $\mathrm{CH}_{2} \mathrm{Cl}_{2}$ and added into a $500 \mathrm{ml}$ threenecked round-bottom flask equipped a magnetic stirrer, condenser and constant pressure dropping funnel. Next, $\mathrm{Et}_{3} \mathrm{~N}(8.3 \mathrm{ml})$ was introduced into the mixture and stirred at room temperature for $10 \mathrm{~min}$. Thereafter, $1,1^{\prime}$-ferrocenedicarbonly chloride $(0.03 \mathrm{~mol})$, which was dissolved in $50 \mathrm{ml} \mathrm{CH}_{2} \mathrm{Cl}_{2}$, was added dropwise. Moreover, the reaction mixture was stirred at room temperature for $12 \mathrm{~h}$ under the nitrogen protection. Then, the brown solution was poured into $500 \mathrm{ml}$ methanol with stirring after filtered and washed thoroughly with methanol, the resulting product was dried at $60^{\circ} \mathrm{C}$ under vacuum to a consent mass (yield: $85 \%$ ), which is named as PFDCHQ. The preparation route of PFDCHQ is shown in Scheme1. 


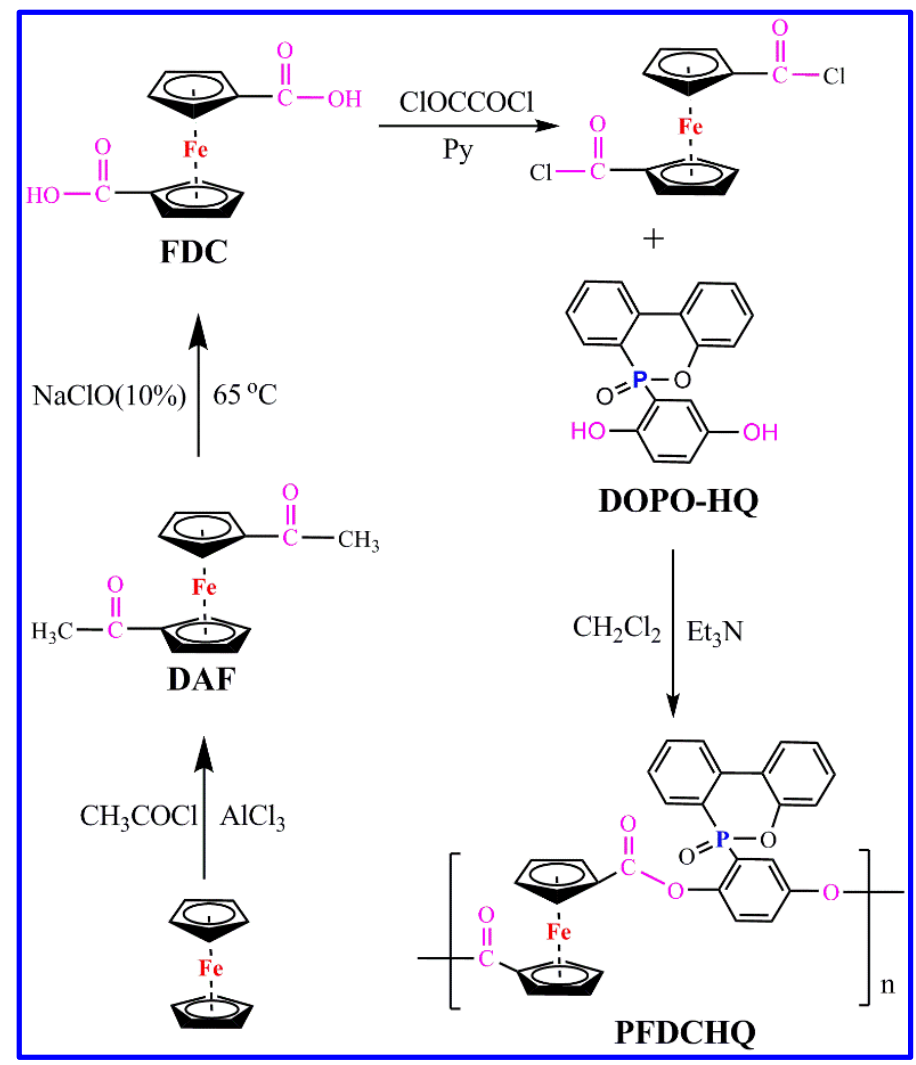

Scheme 1. Synthetic route to PFDCHQ

\subsection{Preparation of EP/PFDCHQ composites}

Briefly, the preparation of epoxy composites with $5 \mathrm{wt} \%$ PFDCHQ was as follows: epoxy resin $(50.0 \mathrm{~g})$ and PFDCHQ (2.63 g) were added into a $150 \mathrm{ml}$ flask with $20 \mathrm{ml} \mathrm{dry} \mathrm{CH}_{2} \mathrm{Cl}_{2}$ and stirred 10 min. After a homogeneous mixture was obtained, and then placed to the rotary evaporators at $70{ }^{\circ} \mathrm{C}$ to remove the $\mathrm{CH}_{2} \mathrm{Cl}_{2}$ solvent. Next, m-PDA (5.0 g) was added in the mass ratio 10: 1 of EP. After that, the mixture was stirred at $80^{\circ} \mathrm{C}$ under reduced pressure until no bubbles emerged. Subsequently, it was poured into a preheated standard polytetrafluoroethylene (PTFE) mold at 80 ${ }^{\circ} \mathrm{C}$. The mixture was cured at $80^{\circ} \mathrm{C}$ for $3 \mathrm{~h}, 100^{\circ} \mathrm{C}$ for $2 \mathrm{~h}$ and then $120^{\circ} \mathrm{C}$ for $3 \mathrm{~h}$. After curing, the samples were cooled to room temperature and the EP/PFDCHQ was obtained. The formulas of EP/PFDCHQ composites are listed in Table 1. Other samples were prepared in the same procedure. A schematic representation of the preparation process of EP/PFDCHQ composites is shown in Scheme 2. 


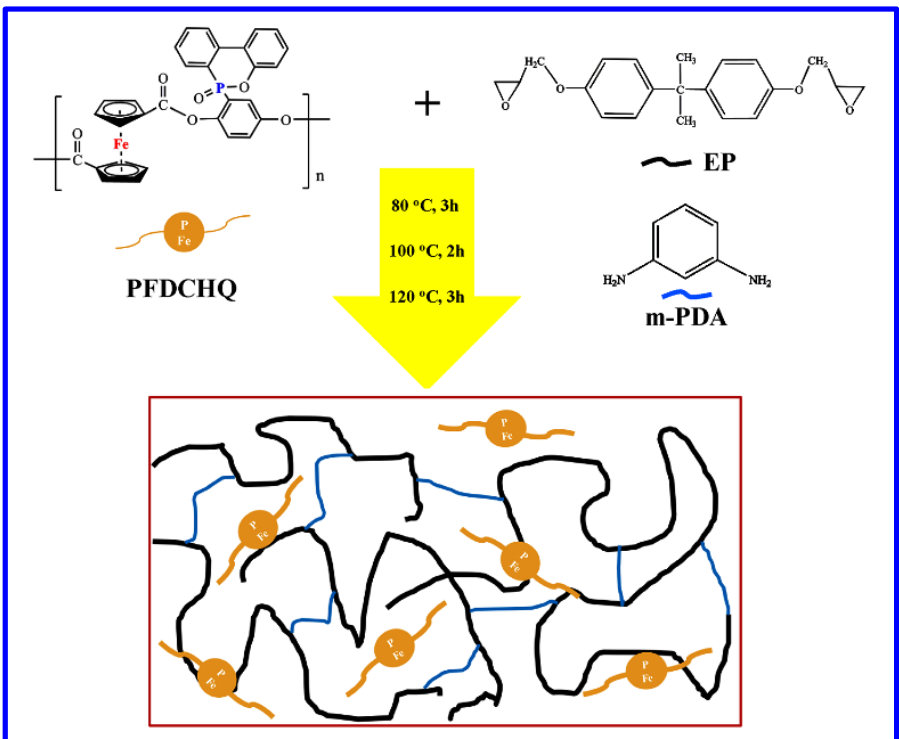

Scheme 2. A schematic representation of the preparation process of EP/PFDCHQ composites

\subsection{Characterization}

Fourier Translation Infrared Spectroscopy (FTIR) of PFDCHQ and its intermediate on a $\mathrm{KBr}$ pellet were analyzed on a FTIR spectrometer (Nicolet 5700) over the wavenumber from 400 to 4000 $\mathrm{cm}^{-1}$.

${ }^{1} \mathrm{H}$ NMR and ${ }^{31} \mathrm{P}$ NMR spectra were performed on Bruker Avance 600 spectrometer $(600 \mathrm{MHz})$, using DMSO- $\mathrm{d}_{6}$ as solvent.

The glass transition temperature $\left(T_{\mathrm{g}}\right)$ of PFDCHQ with $\sim 5 \mathrm{mg}$ was measured by differential scanning calorimeter (DSC) on Jupiter STA 449C thermal analyzer (Netzsch, Germany) with a heating rate of $10^{\circ} \mathrm{C} / \mathrm{min}$ ranging from $25^{\circ} \mathrm{C}$ to $200^{\circ} \mathrm{C}$ under nitrogen atmosphere.

Table 1. Formulation of EP/PFDCHQ composites

\begin{tabular}{lllll}
\hline & & & \multicolumn{2}{l}{ PFDCHQ } \\
\cline { 4 - 5 } Samples & EP $(\mathrm{g})$ & m-PDA $(\mathrm{g})$ & (g) & $($ wt\%) \\
\hline EP-0 & 50 & 5.0 & - & - \\
EP-3 & 50 & 5.0 & 1.55 & 3.0 \\
EP-4 & 50 & 5.0 & 2.08 & 4.0 \\
EP-5 & 50 & 5.0 & 2.63 & 5.0 \\
EP-6 & 50 & 5.0 & 3.19 & 6.0 \\
EP-7 & 50 & 5.0 & 3.76 & 7.0 \\
\hline
\end{tabular}

The DSCQ2000 (TA Instrument company, USA) was used to study $T_{\mathrm{g}}$ of EP and its composite under nitrogen. All samples were heated from room temperature to $150^{\circ} \mathrm{C}$ at a heating rate $10^{\circ} \mathrm{C} / \mathrm{min}$ and keeping for $5 \mathrm{~min}$, and then cooled to room temperature at $-20^{\circ} \mathrm{C} / \mathrm{min}$. A second scanning was conducted at the same heating rate as the first time from room temperature to $150^{\circ} \mathrm{C}$.

The molecular weight and their distribution were determined by Gel Permeation Chromatography (GPC) with an Agilent 1200SERIES instrument using THF as eluent at a flow rate 
of $1.000 \mathrm{ml} / \mathrm{min}$.

The thermogravimetric analysis (TGA) of samples with $\sim 5 \mathrm{mg}$ was carried out with STA6000 simultaneous thermal analyzer (PerkinElmer, USA) from $40^{\circ} \mathrm{C}$ to $700^{\circ} \mathrm{C}$ at a heating rate of 10 ${ }^{\circ} \mathrm{C} / \mathrm{min}$ under nitrogen.

The pyrolysis behavior (Py-GC/MS) of the PFDCHQ was tested with DANI MASTER GC-TOF-MS system combined with a pyrolyzer (CDS5200). The samples ( $\sim 3 \mathrm{mg}$ ), packed in a quartz tube capillary using the platinum coil attachment, were heated from ambient temperature to $700{ }^{\circ} \mathrm{C}$ at a rate of $1000^{\circ} \mathrm{C} / \mathrm{s}$ and kept at this state for 20 seconds. The Py/GC interface temperature was set at $100^{\circ} \mathrm{C}$. The transfer line temperature was set at $260^{\circ} \mathrm{C}$. The injector temperature was set at $280^{\circ} \mathrm{C}$ and operated in the split mode (split ratio 1000: 1) with helium as carrier gas. The detailed data were analyzed using the NIST Mass Spectral Search Program and the NIST library was employed as the standard spectral library to match the volatile pyrolysis product recorded from the analysis.

Thermogravimetric analysis/fourier transform infrared spectra (TG-FTIR) was performed on a STA6000 simultaneous thermal analyzer (PerkinElmer, USA) at a heating rate of $10^{\circ} \mathrm{C} / \mathrm{min}$ from $40^{\circ} \mathrm{C}$ to $700^{\circ} \mathrm{C}$ with $\sim 20 \mathrm{mg}$ powder samples under nitrogen atmosphere.

The limiting oxygen index (LOI) values of the samples were measured by a JF-3 oxygen index meter (Nanjing Jionglei Instrument Equipment Co., Ltd) according to the standard of ASTM D 2863-97 with the three dimensions size of $100.0 \times 6.5 \times 3.2 \mathrm{~mm}^{3}$.

UL-94 vertical burning tests were performed on a vertical burning test instrument (Nanjing Jionglei Instrument Equipment Co., Ltd) based on the standard of ASTM D 3801 with the three dimensions size of $130.0 \times 13.0 \times 3.2 \mathrm{~mm}^{3}$.

The cone calorimeter test was carried out on a FTT Standard Cone Calorimeter (Fire Testing Technology, UK) according to ISO 5660 under an external heat flux of $35 \mathrm{~kW} / \mathrm{m}^{2}$ with sample dimensions of $100.0 \times 100.0 \times 3.0 \mathrm{~mm}^{3}$.

The char residues of EP and EP/PFDCHQ composites after the UL-94 test were investigated on a TM-3000 (Hitachi, Japan) desktop scanning electron microscope (SEM).

The PIT501J LCD plastic Charpy impact testing machine (Shenzhen million Test Equipment Co., Ltd.) was utilized to measure the impact performance of pure EP and EP/PFDCHQ composites with their dimensions of $80.0 \times 10.0 \times 4.0 \mathrm{~mm}^{3}$, according to GB/T1043-2008. The tensile strength was performed on ETM105D $100 \mathrm{KN}$ computer-controlled electronic universal testing machine (WANCE GROUP) with a testing speed of $20 \mathrm{~mm} / \mathrm{min}$, depending on GB/T1040.3-2006.

The fracture surface of EP/PFDCHQ composites was carried on the Ultra55 scanning electron microscope (SEM). 


\section{Results and discussion}

\subsection{Characterization of PFDCHQ}

The structure of PFDCHQ was confirmed by FTIR, ${ }^{1} \mathrm{H}$ NMR and ${ }^{31} \mathrm{P}$ NMR. Some specific absorption peaks appear from DOPO-HQ (Fig.1(a)): $1595 \mathrm{~cm}^{-1}$ (P-Ph), $1197 \mathrm{~cm}^{-1}$ (P=O), $924 \mathrm{~cm}^{-1}(\mathrm{P}-\mathrm{O}-\mathrm{Ph}$ ) [38]. In case of PFDCHQ, these characteristic peaks still exist. The peaks at $3107,1583 \mathrm{~cm}^{-1}$ (benzene ring) and 1450, 832, $493 \mathrm{~cm}^{-1}$ (Cp ring) [39] are clearly observed in the FTIR spectrum of PFDCHQ. In addition, the most significant absorptions are observed at $1737 \mathrm{~cm}^{-1}$ and $1092 \mathrm{~cm}^{-1}, 1181 \mathrm{~cm}^{-1}$, $1274 \mathrm{~cm}^{-1}$ corresponding to the $\mathrm{C}=\mathrm{O}$ and $\mathrm{C}-\mathrm{O}-\mathrm{C}$ respectively [12], indicating the existence of ester group. In the ${ }^{1} \mathrm{H}$ NMR spectrum of PFDCHQ (see Fig.1 (b)), the peaks ranging from 8.09 to 7.10 $\mathrm{ppm}$ are ascribed to the protons on the benzene ring. The peaks from 5.50 to $4.01 \mathrm{ppm}$ belong to the protons on the $\mathrm{Cp}$ ring. Furthermore, PFDCHQ exhibits a single peak at $33.9 \mathrm{ppm}$ in ${ }^{31} \mathrm{P} N M R$ spectrum (Fig. 1(c)). All the results of FTIR, ${ }^{1} \mathrm{H}$ NMR and ${ }^{31} \mathrm{P}$ NMR state that PFDCHQ is obtained successfully.
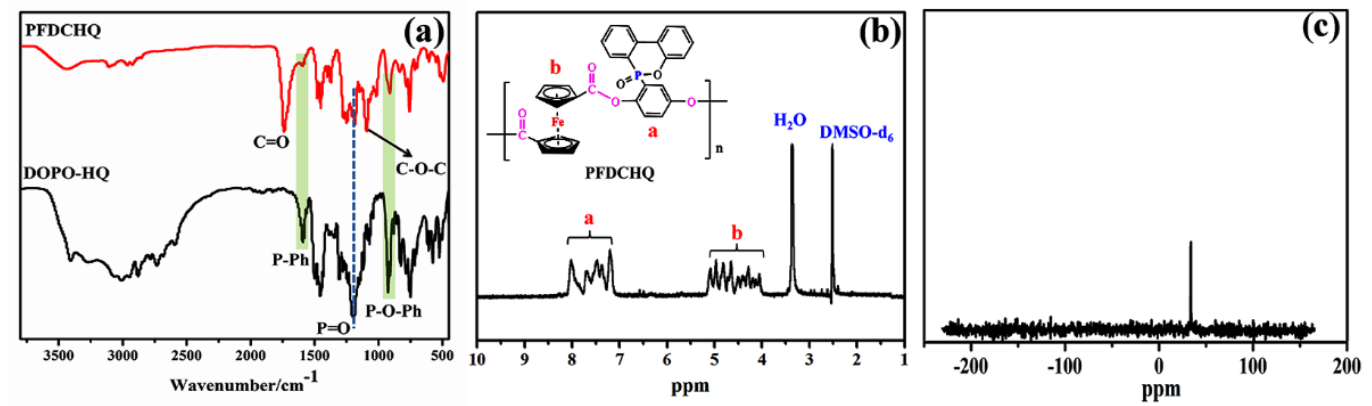

Fig. 1. (a) FTIR spectra of DOPO-HQ and PFDCHQ, (b) ${ }^{1} \mathrm{H}$ NMR spectrum and (c) ${ }^{31} \mathrm{P}$ NMR spectrum of PFDCHQ

The GPC and DSC curves of PFDCHQ are showed in Fig. S3. The weight average molecular weight $\left(M_{\mathrm{w}}\right)$ of PFDCHQ is $10030 \mathrm{~g} / \mathrm{mol}$ and a number molecular weight $\left(M_{\mathrm{n}}\right)$ is $6082 \mathrm{~g} / \mathrm{mol}$, accompanied by the polydispersity $M_{\mathrm{w}} / M_{\mathrm{n}}$ of 1.649 . The glass transition temperature $\left(T_{\mathrm{g}}\right)$ value of $92.4{ }^{\circ} \mathrm{C}$ suggests a relatively high temperature resistance of PFDCHO.

\subsection{Thermal and pyrolysis behavior of PFDCHQ}

The TGA/DTG curves of PFDCHQ in both nitrogen and air are shown in Fig. 2. Based on Fig. 2(a), there are two thermal degradation stages. The first one ranges from 230.6 to $326.6{ }^{\circ} \mathrm{C}$, and a weight loss of $5 \mathrm{wt} \%$ occurs due to the thermal cleavage of ester bond and the early thermal decomposition of some PFDCHQ with low-molecular weight, generating DOPO and ferrocenebased segments. The main degradation stage takes place from 342.4 to $597.5^{\circ} \mathrm{C}$, accompanied by the temperature of maximum mass loss rate $\left(T_{\max }\right)$ around $481.2^{\circ} \mathrm{C}$ and a weight loss of $35 \mathrm{wt} \%$. At this stage, the DOPO-based segments are mainly decomposed into dibenzofuran, $\mathrm{PO}$ and $\mathrm{PO}_{2}$ radicals in nitrogen environment due to the lack of oxygen. According to the TG-FTIR data (Fig. 3), partial ferrocene-containing segments begin to decompose above $390^{\circ} \mathrm{C}$. As for the thermal degradation of PFDCHQ in air (Fig. 2 (b)), the more complex thermal-oxide degradation process can be seen. The initial decomposition temperature $\left(T_{-5 \%}\right)$ of PFDCHQ is advanced to $269.1^{\circ} \mathrm{C}$ due to the existence of oxygen. The first main decomposition stage from $218.9^{\circ} \mathrm{C}$ to $523.4^{\circ} \mathrm{C}$ with a 
weight loss of $38.5 \%$, including series of thermal degradation stages from DTG curve, can be assigned to the decomposition of low-molecule weight PFDCHQ, cleavage of ester bonds, and the further degradation of ferrocene or phosphorus-containing structures, generating an unstable carbonaceous layer. The second main thermal degradation stage from $523.4-622.5^{\circ} \mathrm{C}$ originates from the further thermal-oxide decomposition of the unstable carbonaceous layer. Moreover, the char residues of PFDCHQ in nitrogen and air atmosphere are $60.3 \mathrm{wt} \%$ and $20.1 \mathrm{wt} \%$ at $700{ }^{\circ} \mathrm{C}$, respectively, indicating that PFDCHQ has better thermal stability during high-temperature stage in nitrogen atmosphere.
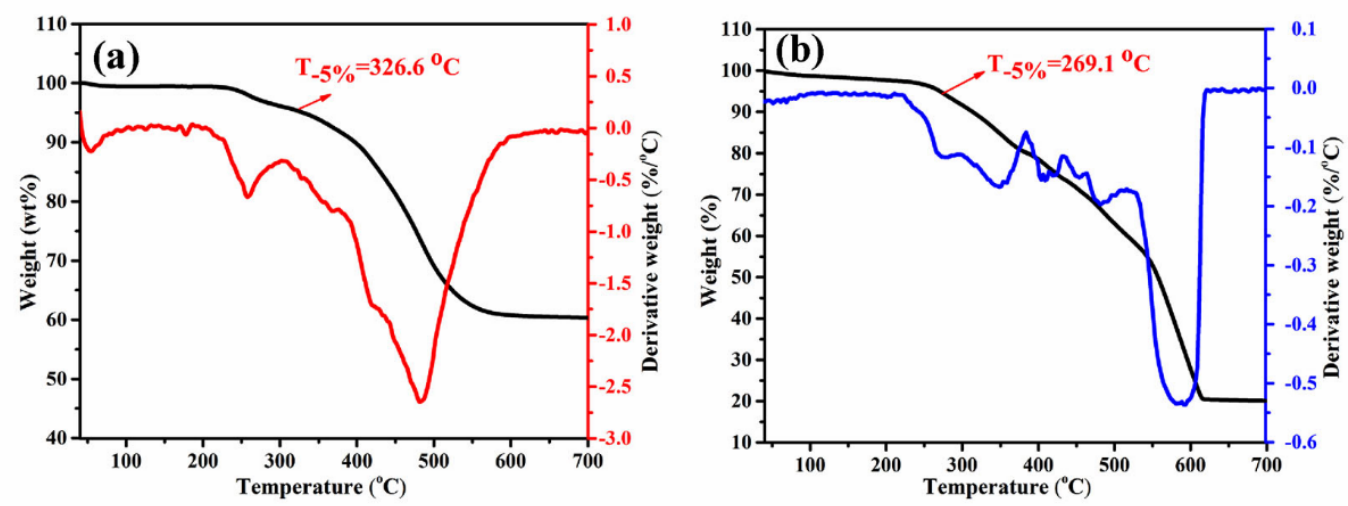

Fig. 2. TG and DTG curves of PFDCHQ in nitrogen (a) and air (b) atmosphere

TG-FTIR was usually used to analyze the gaseous products during the thermal degradation. The FTIR spectra of pyrolysis products of PFDCHQ at different temperatures are shown in Fig. 3 . The relevant characteristic absorbing peaks appear at $3738 \mathrm{~cm}^{-1}\left(\mathrm{H}_{2} \mathrm{O}\right), 3015 \mathrm{~cm}^{-1}$ ( $\mathrm{Cp}$ ring), $2360 \mathrm{~cm}^{-1}$ $\left(\mathrm{CO}_{2}\right)$ and $1508 \mathrm{~cm}^{-1}$ (aromatic compounds and $\mathrm{Cp}$ ring) [40, 41]. Before $250^{\circ} \mathrm{C}$, there is no obvious peak of $\mathrm{CO}_{2}$ indicating that PFDCHQ has a good thermal stability. With the temperature increasing to $390^{\circ} \mathrm{C}$, the new absorbing peak at $3015 \mathrm{~cm}^{-1}$ ( $\mathrm{Cp}$ ring) comes into sight [21], which is attributed to the decomposition of ferrocene-containing compounds at high temperature. New peaks of $1262 \mathrm{~cm}^{-1}$ and $1180 \mathrm{~cm}^{-1}$ at $400{ }^{\circ} \mathrm{C}$ can be attributed to $\mathrm{P}=\mathrm{O}$ and $\mathrm{C}-\mathrm{O}-\mathrm{C}$ generated from DOPO-containing segments $[42,43]$. When the temperature rises to $500{ }^{\circ} \mathrm{C}$, the absorption intensity of $\mathrm{P}=\mathrm{O}, \mathrm{C}-\mathrm{O}-\mathrm{C}$ and aromatic compounds are weakened, and it can be inferred that the rest of $\mathrm{P}$ element and aromatic compounds remain in the condensed phase and take part in the formation of char residue [44].
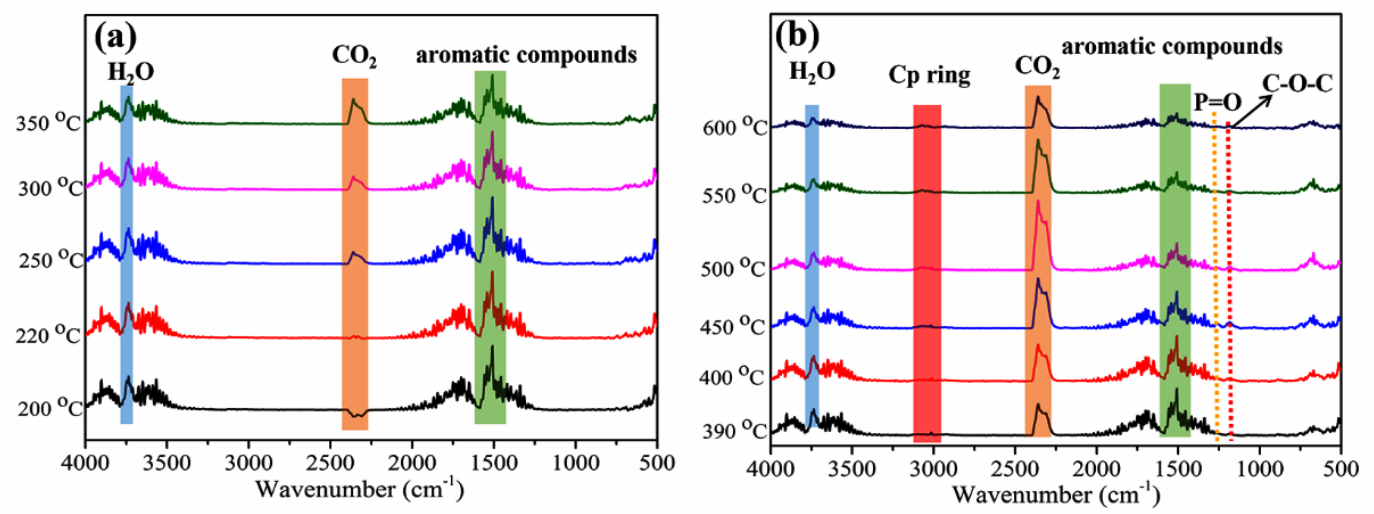

Fig. 3. The TG-FTIR spectra of volatilized products at different temperatures during thermal decomposition of PDPFDE under $\mathrm{N}_{2}$ 
To further identify the thermal degradation mechanism of PFDCHQ, Py-GC/MS test was performed. The total ion chromatogram and analysis data are shown in Fig. 4 and Table S1. The predominant decomposition volatiles of PFDCHQ are ethanol, phenol, 2-methyphenol, biphenylene, dibenzofuran, o-hydroxybiphenyl and fluorine, corresponding to the peaks 1, 2, 3, 6, 7,8 and 9, respectively. Impressively, some aromatic compounds are produced, such as naphthalene (peak 4), fluorine (peak 9) and phenanthrene (peak 10).

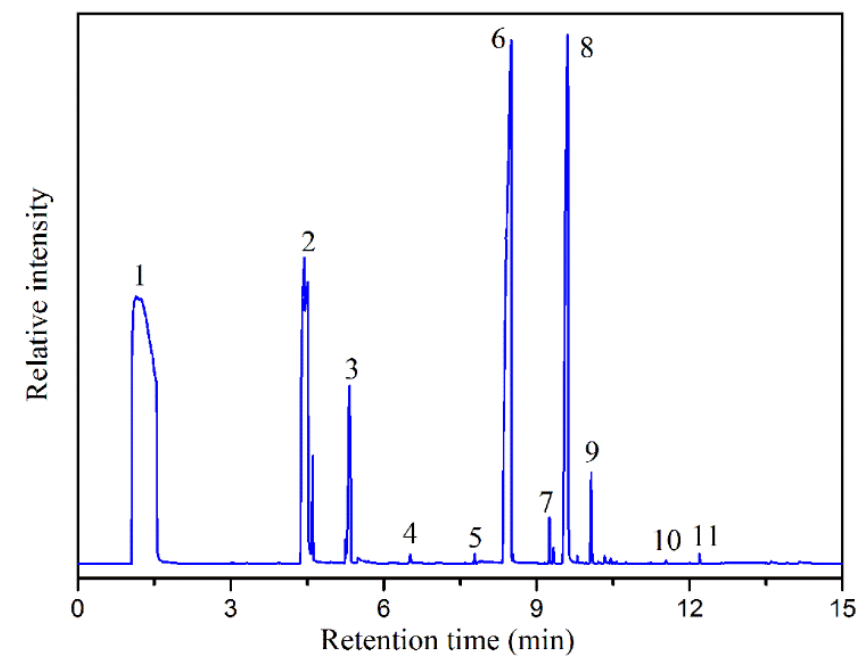

Fig. 4. Total ion chromatogram of PFDCHQ

The pyrolysis mechanism of PFDCHQ can be further elucidated based on the cracking product in $\mathrm{Py}-\mathrm{GC} / \mathrm{MS}$ and shown in Scheme 3. With the increasing temperature, the $\mathrm{O}=\mathrm{C}-\mathrm{O}$ bond is firstly dissociated; decomposing into two parts of ferrocene-based group and DOPO-containing species. Subsequently, the groups on the two sides of ferrocene derivatives begin to cleave, producing $\mathrm{CO}_{2}$ and ferrocene. Besides, the derivatives containing DOPO groups begin to decompose to produce 6-methyl-6H-dibenzo[c,e][1,2]oxaphosphinine 6-oxide (peak 11 in Fig. 4). It is possible to speculate that 6-methyl-6H-dibenzo[c,e][1,2]oxaphosphinine 6-oxide could release DOPO free radical, then proceed to generate $\mathrm{PO}_{2}$ and $\mathrm{PO}$ radicals, accompanied by biphenylene and dibenzofurans, respectively [45, 46], since the biphenylene (peak 6) and dibenzofuran (peak 7) were detected in the chromatogram of PFDCHQ (Fig. 4). The $\mathrm{PO}_{2}$ and $\mathrm{PO}$ radicals can contribute to flame inhibition by trapping active $\mathrm{H}$ and $\mathrm{HO}$ free radicals and stopping the chain reaction [47]. The analysis result of Py-GC/MS is consistent with the TG-FITR and TG data of PFDCHQ under nitrogen condition. 


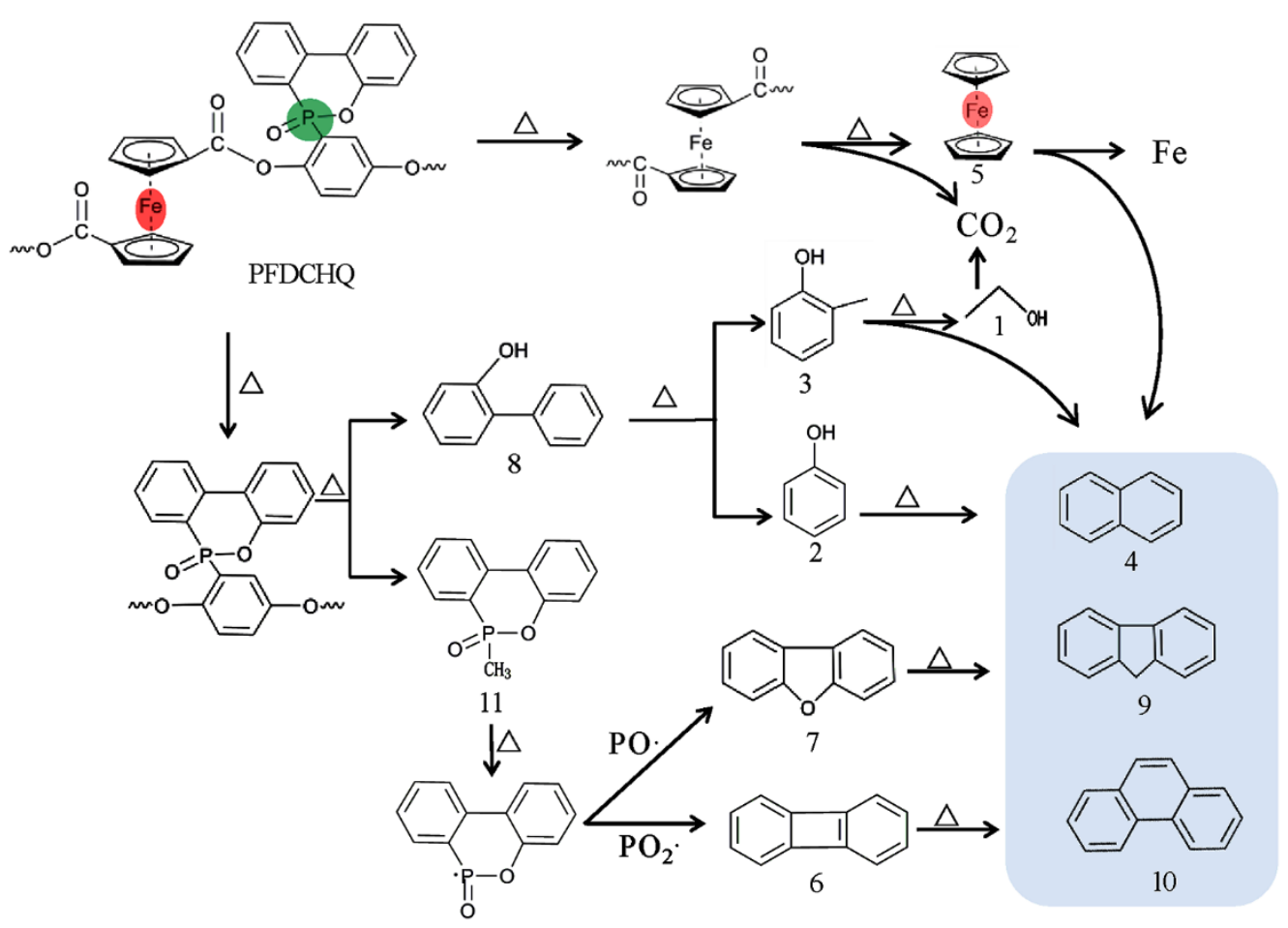

Scheme. 3. Possible pyrolytic route of PFDCHQ during thermal degradation

\subsection{Thermal properties of EP/PFDCHQ composites}

Thermogravimetric analysis is the most common method for evaluation of the thermal decomposition property of polymeric materials. Fig. 5 illustrates the TG and DTG curves of EP-0, EP-5 and EP- 6 in nitrogen atmosphere. The onset degradation temperature $\left(T_{d}\right)$ of samples is evaluated by the temperature at $5 \mathrm{wt} \%$ weight loss $\left(T_{-5 \%}\right)$ and the char residues at $700{ }^{\circ} \mathrm{C}$ are obtained from the TG curves; the temperature at maximum weight loss rate $\left(T_{\max }\right)$ of samples is obtained from the DTG curves. Some important data are listed in Table 2. The DTG curves of EP-0, EP-5 and EP-6 present one decomposition step with maximum mass loss rate at 368.2, 351.5 and $357.1^{\circ} \mathrm{C}$ respectively. The $T_{-5 \%}$ of EP- 5 and EP- 6 are lower than EP-0, which may be attributed to the fact that the introduction of ferrocene group can promote the advanced thermal degradation of epoxy resin [35], which would provide more carbon source to form protective char layer. Combining the self-high-charring properties of PFDCHQ, the resulting char residue of EP-5 (25.1 wt\%) and EP-6 (22.1 wt\%) are both higher than EP-0 (16.8 wt\%) at $700{ }^{\circ} \mathrm{C}$.

Table 2. TGA data of EP-0, EP-5 and EP-6

\begin{tabular}{llll}
\hline Samples & $\mathrm{T}_{-5 \%}\left({ }^{\circ} \mathrm{C}\right)$ & $\mathrm{T}_{\max }\left({ }^{\circ} \mathrm{C}\right)$ & $\begin{array}{l}\text { Char } \\
\left(700{ }^{\circ} \mathrm{C}\right) \mathrm{wt} \%\end{array}$ \\
\hline EP-0 & 319.3 & 368.2 & 16.8 \\
EP-5 & 296.9 & 351.5 & 25.1 \\
EP-6 & 283.1 & 357.1 & 22.1 \\
\hline
\end{tabular}

Another important parameter for evaluating the thermal stability of epoxy resin is glass transition temperature $\left(T_{\mathrm{g}}\right)$. Thus DSC results of EP/PFDCHQ composites are shown in Fig. 6. The $T_{\mathrm{g}}$ value of 
EP-0 is $122^{\circ} \mathrm{C}$ and the $T_{\mathrm{g}}$ value of EP- 5 increases to $131^{\circ} \mathrm{C}$ with $5 \mathrm{wt} \%$ PFDCHQ loading. This may be attributed to the rigid structure (ferrocene unit and benzene ring) of PFDCHQ, which can limit the movement of epoxy resin molecular chain [48]. As the content of PFDCHQ reaches to $6 \mathrm{wt} \%$, the $T_{\mathrm{g}}$ value of EP-6 decrease slightly due to the aggregation of excessive PFDCHQ.
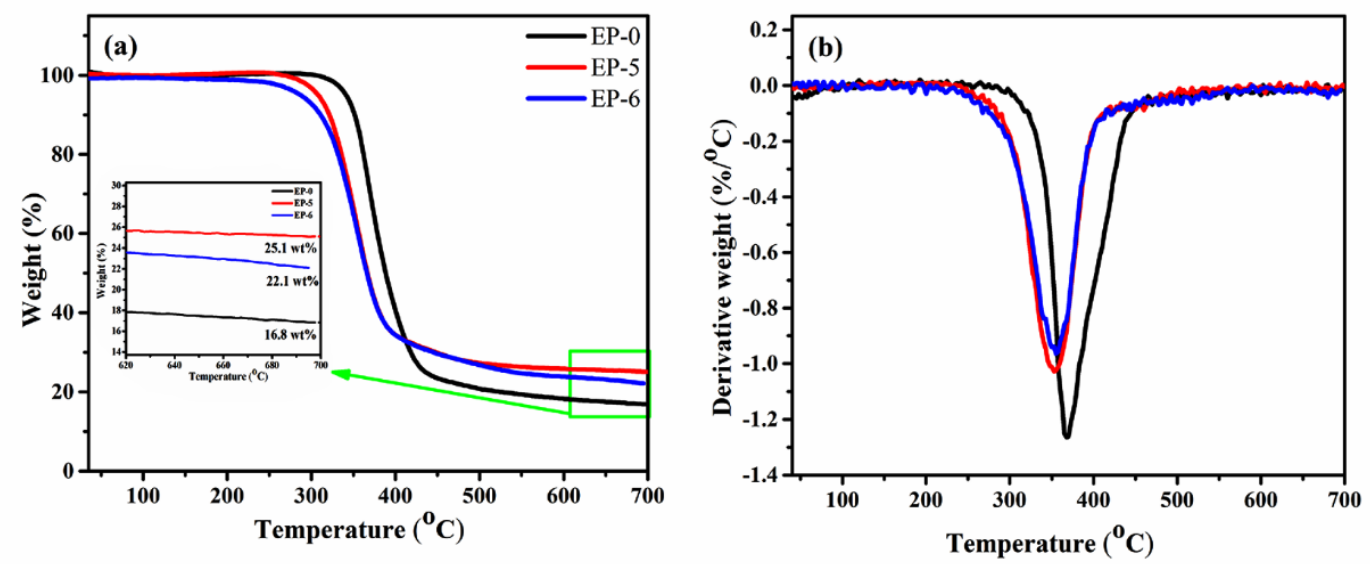

Fig. 5. TG (a) and DTG (b) curves of EP-0, EP-5 and EP-6 in nitrogen

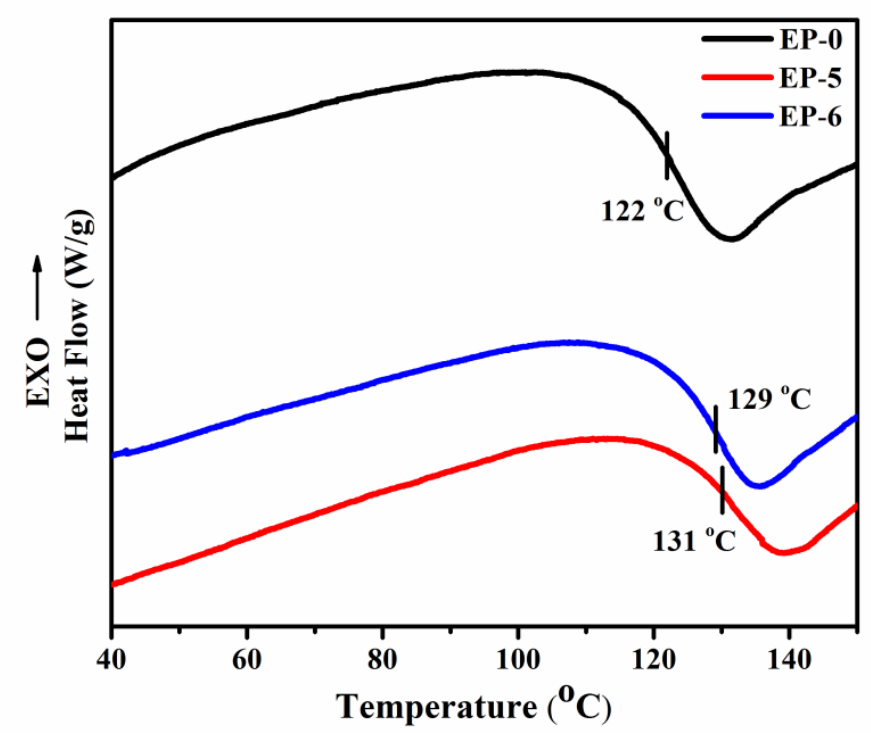

Fig. 6. DSC curves of EP-0, EP-5 and EP-6

\subsection{Fire behavior and flame-retardancy}

The limiting oxygen index (LOI) and UL-94 test are widely used to evaluate the flammability of materials. The LOI values and the experiment results of UL-94 are shown in Table 3. The EP-0 burns quickly after ignition in both LOI and UL-94 tests. When adding 5 wt\% PFDCHQ, the LOI value of EP- 5 can reach $32.0 \%$ and easily pass the V-0 rating. The real-time digital photos of some samples (EP-0, EP-3, EP-5 and EP-6) during UL-94 tests are shown in Fig. 7. After evacuating the source of fire, EP-0 continues to burn without a sign of extinguish, while EP-5 was extinguished naturally in $10 \mathrm{~s}$, indicating that the incorporation of PFDCHQ do improve the fire retardancy for $E P$, which is attributing to the three reasons: 1) The $\mathrm{PO}$ and $\mathrm{PO}_{2}$ radicals generated from DOPO 
structure inhibit flame by trapping $\mathrm{H}$ and $\mathrm{HO}$ fragments; 2 ) The addition of PFDCHQ promote the initial catalytic charring action on the surface of EP-5 [49]; 3) it is notable that an obvious blowing-out effect can be observed for EP-5, which is very important to wipe the flame away rapidly in UL-94 testing [50-52]. However, the LOI values and UL-94 ratings of EP-6 and EP-7 decrease probably due to two reasons: 1 ) the aggregation of excessive PFDCHQ; 2) the more ferrocene groups should result in a faster degradation rate than the charring rate of EP composite during combustion. These results suggest that an appropriate loading amount of PFDCHQ is a key factor for the formation of suitable strong char layer to satisfy the demanded inner volatile gas pressure to blowing-out effect.

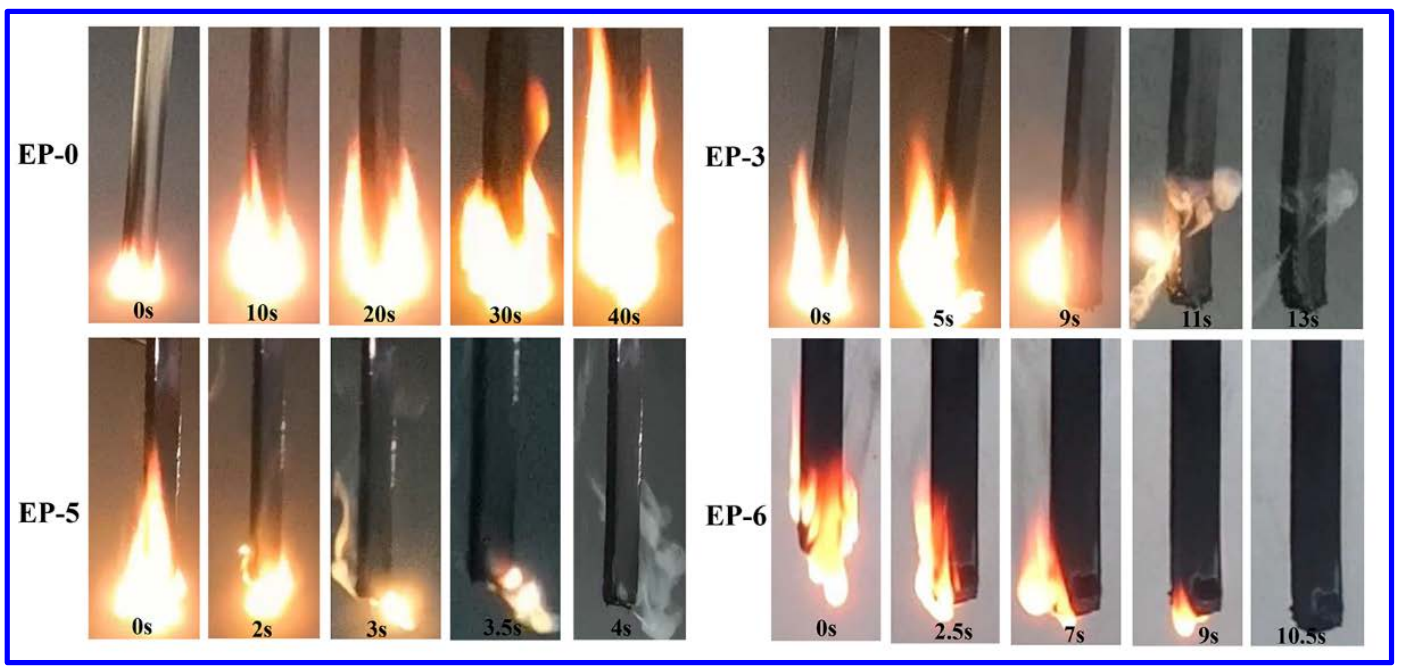

Fig. 7. The digital photos during vertical burning test of EP-0, EP-3, EP-5 and EP-6

Table 3. LOI and UL-94 data of EP and its composites

\begin{tabular}{llllll}
\hline & & \multicolumn{2}{l}{ UL-94 } & & \\
\cline { 2 - 6 } Samples & LOI (\%) & $\mathrm{t}_{1}$ & $\mathrm{t}_{2}$ & Rating & Dripping \\
\hline EP-0 & $24.5 \pm 0.3$ & $>40$ & - & $\mathrm{NR}$ & NO \\
EP-3 & $29.2 \pm 0.2$ & 13.6 & 5.3 & $\mathrm{~V}-1$ & NO \\
EP-4 & $30.6 \pm 0.4$ & 13.2 & 4.6 & $\mathrm{~V}-1$ & NO \\
EP-5 & $32.0 \pm 0.3$ & 4.0 & 3.1 & $\mathrm{~V}-0$ & NO \\
EP-6 & $30.9 \pm 0.2$ & 10.5 & 2.9 & $\mathrm{~V}-1$ & NO \\
EP-7 & $30.3 \pm 0.3$ & 11.6 & 4.2 & V-1 & NO \\
\hline
\end{tabular}

$t_{1}$ and $t_{2}$ are the extinguish time after two 10 second ignition; NR is no rating.

Cone calorimeter (CC) test is widely used to detect the combustion characteristic of the polymeric materials [53]. Fig. 8 showed the heat release rate (HRR), total heat release (THR), smoke production release (SPR) and mass curves of EP-0, EP- 5 and EP- 6 . Other various important data obtained from measurements in cone calorimeter, such as the time-to-ignition (TTI), peak heat release rate (pHRR), time-to-pHRR (t-pHRR), average effective heat of combustion (AEHC), fire growth rate (FIGRA), average specific extinction area (ASEA) and the char residue yield, are 
summarized in Table 4. The pHRR is one of the most important fire behavior parameters for fire retarding materials. In Fig. $8(\mathrm{a}, \mathrm{b})$, the pHRR of EP-5 and EP-6 reduced to $939.3 \mathrm{~kW} / \mathrm{m}^{2}, 872.3$ $\mathrm{kW} / \mathrm{m}^{2}$, meanwhile the THR decreased to $89.2 \mathrm{MJ} / \mathrm{m}^{2}$ and $83.5 \mathrm{MJ} / \mathrm{m}^{2}$ respectively when compared to EP-O. The reason is probably attributed to $\mathrm{PO}$ and $\mathrm{PO}_{2}$ free radicals, produced by DOPO structure in PFDCHQ during combustion, which can interrupt the chain reaction by capturing $\mathrm{H}$ and $\mathrm{HO}$ fragments $[44,54,55]$. Unfortunately, the results of cone calorimetry test show lower fire retardancy efficiency compared to LOI and UL-94 data. What's more, the FIGRA of EP-5 $8.2 \mathrm{~kW} / \mathrm{m}^{2} \mathrm{~s}$ is higher than that of EP-0 $\left(6.9 \mathrm{~kW} / \mathrm{m}^{2} \mathrm{~s}\right)$. This may be due to the fact that the catalytic degradation effect of ferrocene is slightly stronger than the free radical quenching under continuously forced heating during cone calorimetry test. Fig. 8(c) shows the mass curves of EP-0, EP-5 and EP-6 composites. The higher char residue was obtained for EP-5, illustrating that the char layer is produced by EP- 5 during burning. Furthermore, it is worth noting from the mass curves that EP-5 and EP- 6 begin to decompose earlier than EP-0 due to the catalytic degradation effect of PFDCHQ. The smoke production release (SPR) of EP-0, EP- 5 and EP- 6 are shown in Fig. 8(d). It is found that the SPR of EP- 5 decreases a lot compared to EP-0, suggesting that PFDCHQ could inhibit the production of smoke for epoxy resin to a certain extent.
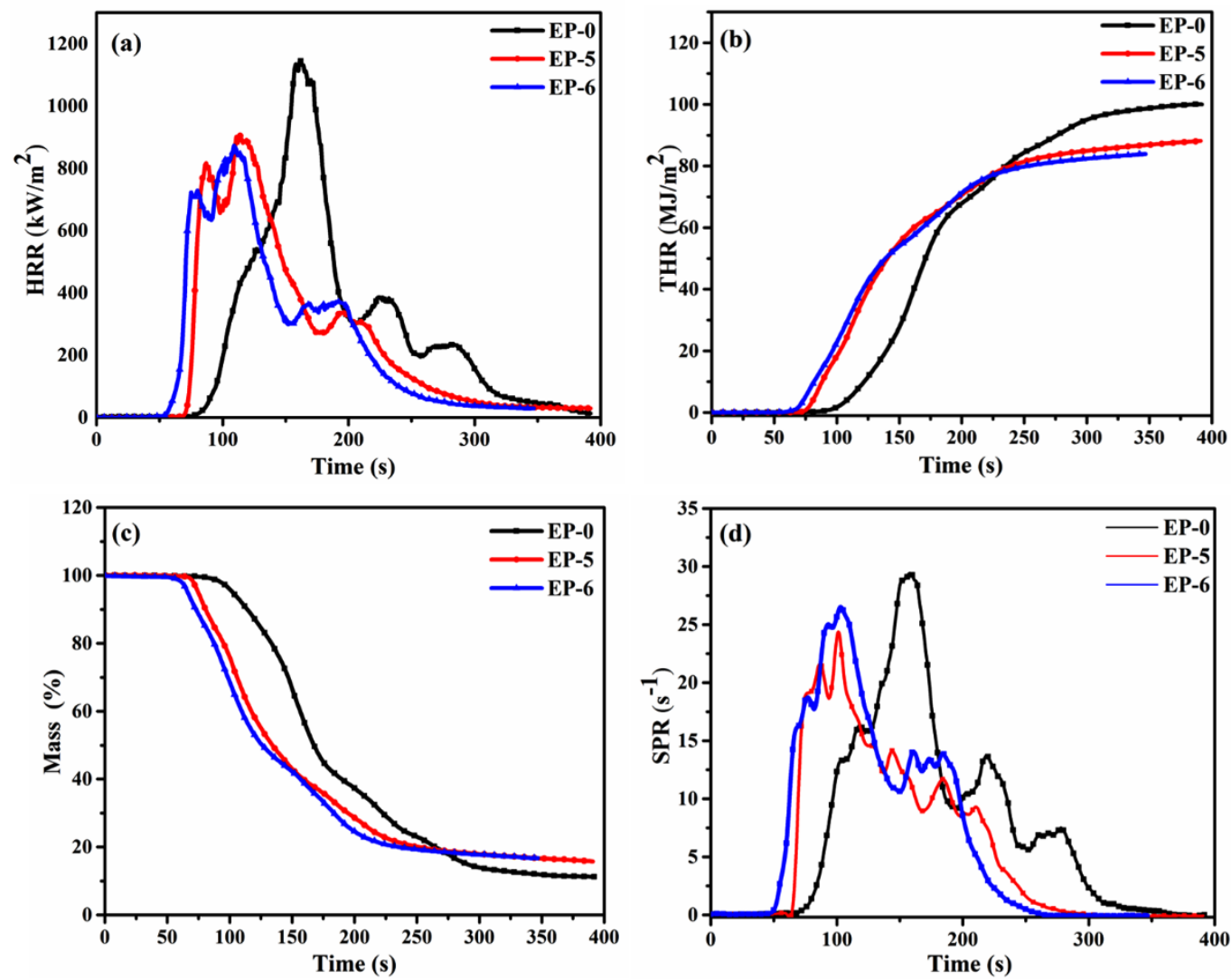

Fig. 8. (a) HRR, (b) THR, (c) Mass loss and (d) SPR curves of EP-0, EP-5 and EP-6 from cone calorimeter tests 
Table 4. Detailed CC data of EP-0, EP-5 and EP-6

\begin{tabular}{llllllll}
\hline Samples & TTI $(\mathrm{s})$ & $\begin{array}{l}\mathrm{t}-\mathrm{pHRR} \\
(\mathrm{s})\end{array}$ & $\begin{array}{l}\mathrm{pHRR} \\
\left(\mathrm{kW} / \mathrm{m}^{2}\right)\end{array}$ & $\begin{array}{l}\text { THR } \\
\left(\mathrm{MJ} / \mathrm{m}^{2}\right)\end{array}$ & $\begin{array}{l}\text { AEHC } \\
(\mathrm{MJ} / \mathrm{kg})\end{array}$ & $\begin{array}{l}\text { ASEA } \\
\left(\mathrm{m}^{2} / \mathrm{kg}\right)\end{array}$ & $\begin{array}{l}\text { Residue } \\
(\mathrm{wt} \%)\end{array}$ \\
\hline EP-0 & $63 \pm 13$ & $170 \pm 9$ & $1146.1 \pm 16.1$ & $99.4 \pm 0.4$ & $24.71 \pm 0.19$ & $695.87 \pm 9.37$ & $10.2 \pm 1.4$ \\
EP-5 & $61 \pm 4$ & $114 \pm 4$ & $939.3 \pm 59.9$ & $89.2 \pm 2.3$ & $22.63 \pm 0.48$ & $588.67 \pm 17.07$ & $15.8 \pm 1.0$ \\
EP-6 & $56 \pm 9$ & $113 \pm 4$ & $872.3 \pm 26.0$ & $83.5 \pm 4.1$ & $21.69 \pm 1.23$ & $623.94 \pm 21.16$ & $14.9 \pm 0.8$ \\
\hline
\end{tabular}

The $\mathrm{CO}_{2}$ and $\mathrm{CO}$ product rate curves of EP-0, EP-5 and EP-6 are shown in Fig. 9. From Fig. 9, it can be seen that the $\mathrm{CO}_{2}$ release rate of EP- 5 and EP- 6 are much lower than EP-0, while their CO production rate are higher than EP-O. The result indicates that the EP/PFDCHQ composites cannot be fully burned due to the existence of $\mathrm{PO}$ and $\mathrm{PO}_{2}$ radicals released by $\mathrm{PFDCHQ}$, which play a distinct fire retardant role in gas phase.
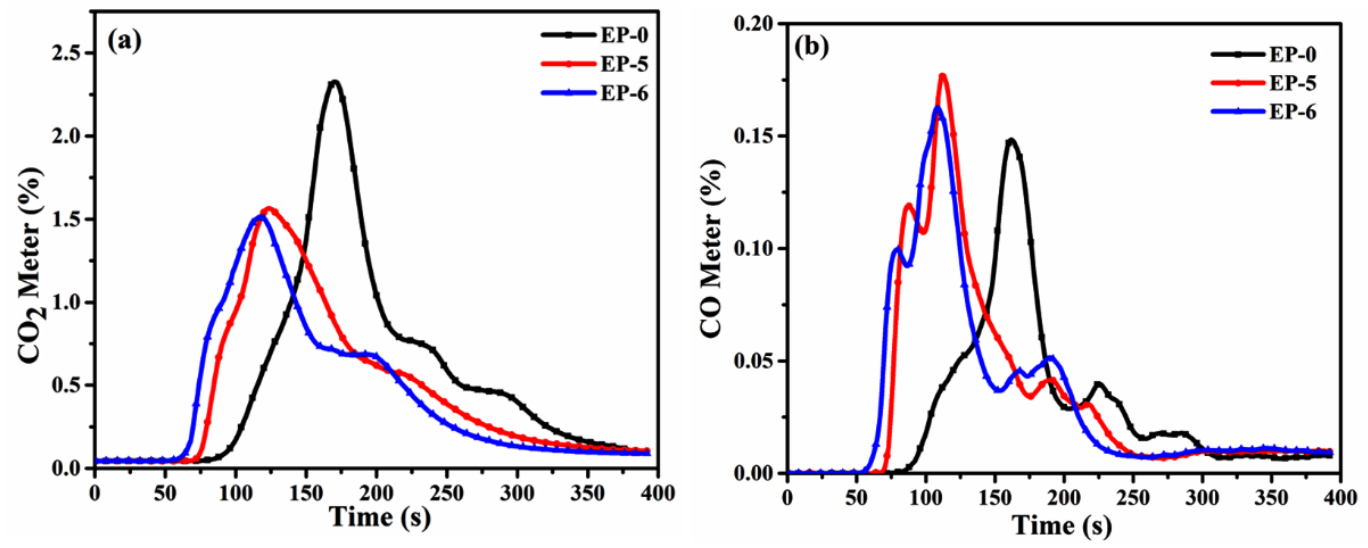

Fig. 9. $\mathrm{CO}_{2}(\mathrm{a})$ and $\mathrm{CO}$ (b) release rate curves of EP-0, EP-5 and EP-6 from cone calorimeter tests

From Table 4, it can be found that the EP-5 and EP- 6 show a slight reduction in TTI and t-pHRR, which may be assigned to the catalysis degradation effect of ferrocene group in PFDCHQ. With respect to the AEHC, when adding $5 \mathrm{wt} \%$, the AEHC shows a slight decrease from 24.71 (EP-0) to $22.63 \mathrm{MJ} / \mathrm{kg}$. The ASEA is used to measure the ability of the material to produce smoke. The ASEA value of EP-5 is $588.67 \mathrm{~m}^{2} / \mathrm{kg}$, which is lower than that of EP-0 ( $\left.695.87 \mathrm{~m}^{2} / \mathrm{kg}\right)$ indicating that PFDCHQ not only can improve the flame retardancy, but also can suppress the smoke-production of EP.

\subsection{Flame retardant mechanism in both condensed and gas phases}

The flame retardant mechanism of EP/PFDCHQ composites was analyzed by the condensed and gas-phase analysis. FTIR spectra of pyrolysis products of EP-0 and EP-5 composites at different temperatures were recorded during TG-FTIR test and are shown in Fig. 10. The main thermal decomposition products of EP-O can be clearly seen, such as $\mathrm{H}_{2} \mathrm{O}\left(3600-4000 \mathrm{~cm}^{-1}\right), \mathrm{CO}_{2}$ (2307$2380 \mathrm{~cm}^{-1}$ ), aromatic compounds $\left(3010-3030,1512,825,742 \mathrm{~cm}^{-1}\right)$ and hydrocarbons (2800-3100 $\mathrm{cm}^{-1}$ and 1100-1250 $\mathrm{cm}^{-1}$ ) [56-58]. For EP-5, The new absorption bands at $1262 \mathrm{~cm}^{-1}$ and 1180 $\mathrm{cm}^{-1}$ belong to the $\mathrm{P}=\mathrm{O}$ and $\mathrm{C}-\mathrm{O}-\mathrm{C}$ structures, respectively. In addition, there are no significant peaks of hydrocarbon for EP-5, indicating lower the smoke-production during combustion. It is also worth noting that the peaks of aromatic compounds $\left(825 \mathrm{~cm}^{-1}\right.$ and $\left.742 \mathrm{~cm}^{-1}\right)$ for EP-5 
(Fig.10(b2)) disappeared, but the peak around $1512 \mathrm{~cm}^{-1}$ remains stronger than that of EP-0, which can be attributed to the aromatic compounds originated from PFDCHQ. This result is consistent with the TG-FTIR (Fig.3) of PFDCHQ.

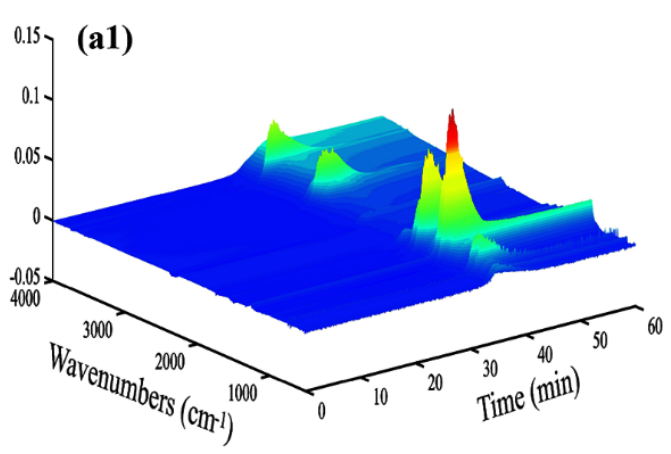

(a2)
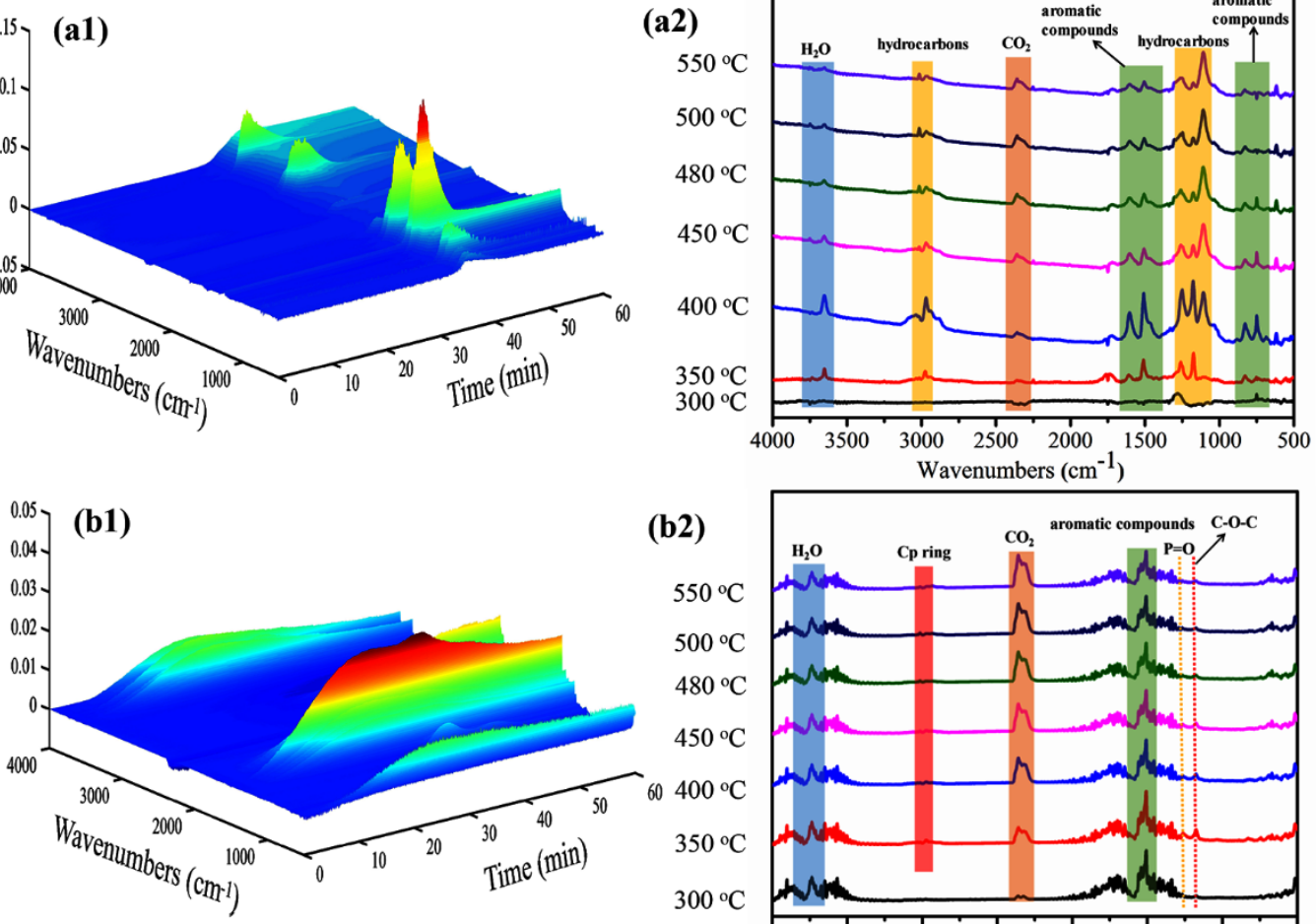

(b2)

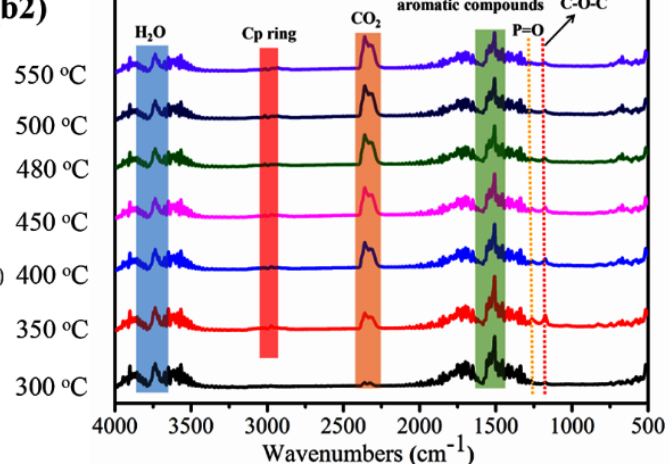

Fig. 10. 3D FTIR and FTIR spectra of the pyrolysis products of EP-0 (a1,a2) and EP-5 (b1,b2) at different temperature

In order to further understand the change of the pyrolysis products, total and some specific products of EP- 0 and EP- 5 are revealed in Fig. 11. It can be seen that the total pyrolysis products for EP-5 are lower than EP-0 (Fig. 11(a)) indicated that PFDCHQ can prevent epoxy resin from further combustion. Furthermore, Fig. 11 (b, c, and d) display the absorbance intensity of $\mathrm{CO}_{2}$, hydrocarbons, and aromatic compounds. Hydrocarbons and aromatic compounds belong to flammable gases and tend to aggregate into smoke particles, which increase the probability of fire accident [59]. Fortunately, the absorbance intensity of hydrocarbons and aromatic compounds from EP-5 are much lower than EP-0, implying that more of them had remained in condensed phase to form the compact protective char layer [60]. Moreover, the production of $\mathrm{CO}_{2}$ from EP-5 is higher than EP-0 and it helps to dilute flammable gases, thereby preventing further combustion of the matrix materials.

Raman spectroscopy, a powerful tool for the characterization of carbonaceous materials, has been applied to analyze the char residues of EP composites. Fig. 12 shows the Raman spectra of EP-O and EP-5. The degree of graphic structure is evaluated by the ratio of $I_{D} / I_{G}$, where $I_{D}$ and $I_{G}$ are the integrated intensities of $D\left(\sim 1360 \mathrm{~cm}^{-1}\right)$ and $G\left(\sim 1590 \mathrm{~cm}^{-1}\right)$ bands [61], respectively. Generally speaking, the lower ration of $I_{D} / I_{G}$ means the higher graphitization degree of char [62]. And the higher graphitized char can effectively retard the flame and protect the inner polymer 
matrix from further burning. The values of $I_{D} / I_{G}$ follow the sequence of EP-0 (1.589) $>$ EP-5

(1.137), illustrating that the addition of PFDCHQ can contribute to form a stable graphic structure char layer.
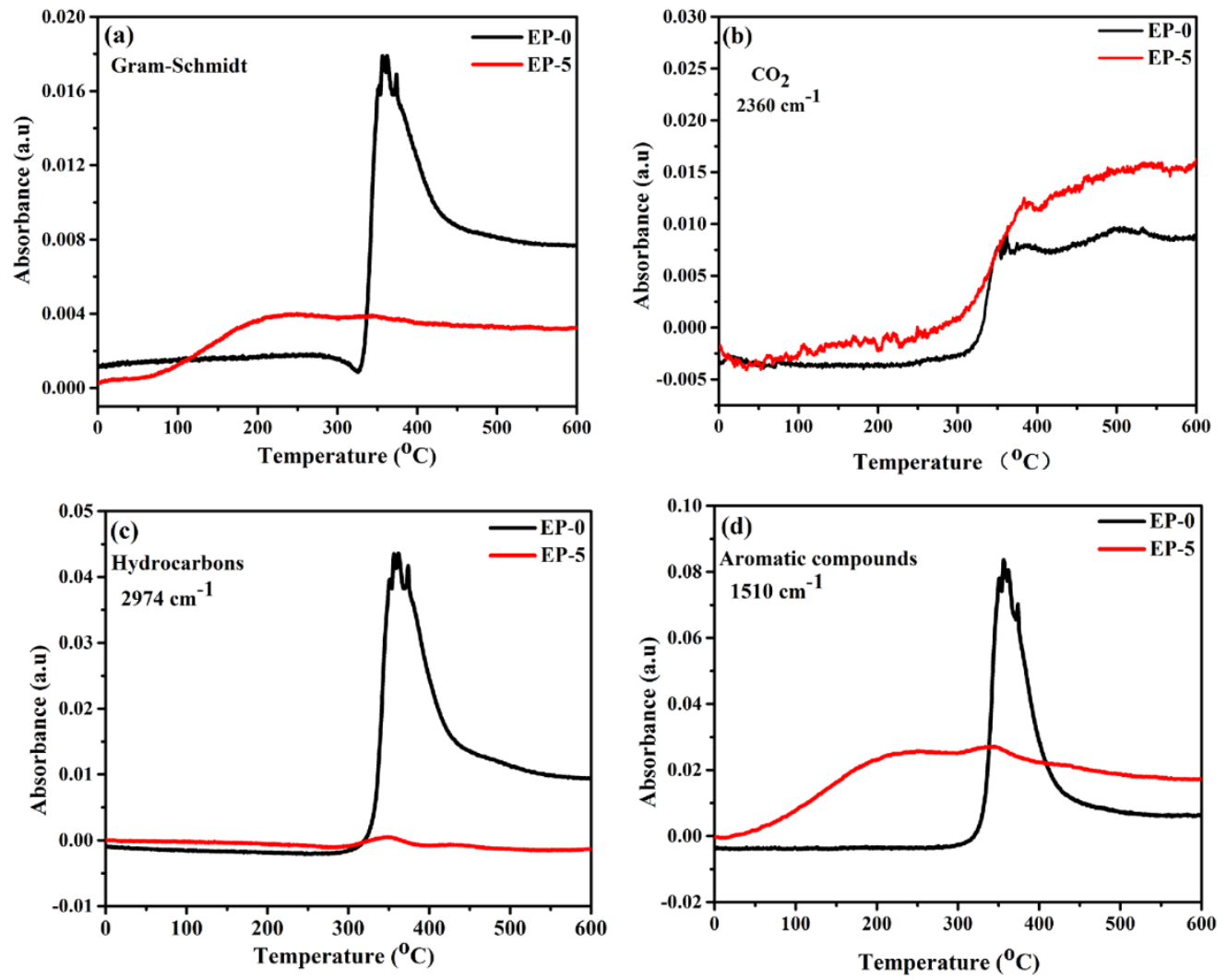

Fig. 11. Absorbance of pyrolysis products for EP-0 and EP-5 versus temperature: (a) gram-schmidt, (b) $\mathrm{CO}_{2}$, (c) hydrocarbons and (d) aromatic compounds
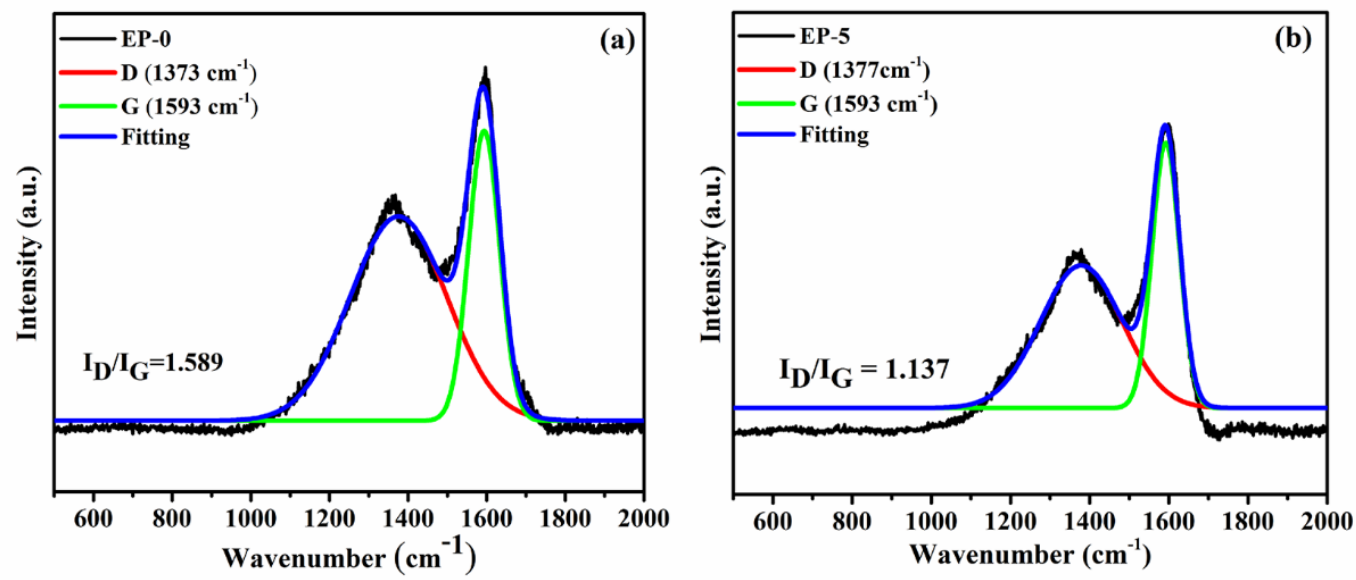

Fig. 12. Raman spectra of char residues of EP-0 and EP-5 composites after UL-94 tests

To further clarify the structure of the fire-resistant barrier on the surface, the char residues of EP0 and EP-5 after UL-94 tests were analyzed after UL-94 texts using FTIR and shown in Fig. 13. It is obvious that the two spectra are different between EP-0 and EP-5. The weak peak at around 1360 
$\mathrm{cm}^{-1}$ of EP-5 is due to the stretching vibration of $\mathrm{P}=\mathrm{O}$ [63]. Meanwhile, the new absorption peak of EP-5 appearing at $885 \mathrm{~cm}^{-1}$ is assigned to the stretching vibrations of P-O-P or P-O-Ph bonds $[64,65]$. These bonds can play a role of cross-linker to link different aromatic species and strengthen carbon layers $[66,67]$. The new peak at $753 \mathrm{~cm}^{-1}$ should belong to $\mathrm{C}-\mathrm{H}$ deformation vibrations of aromatic ring.

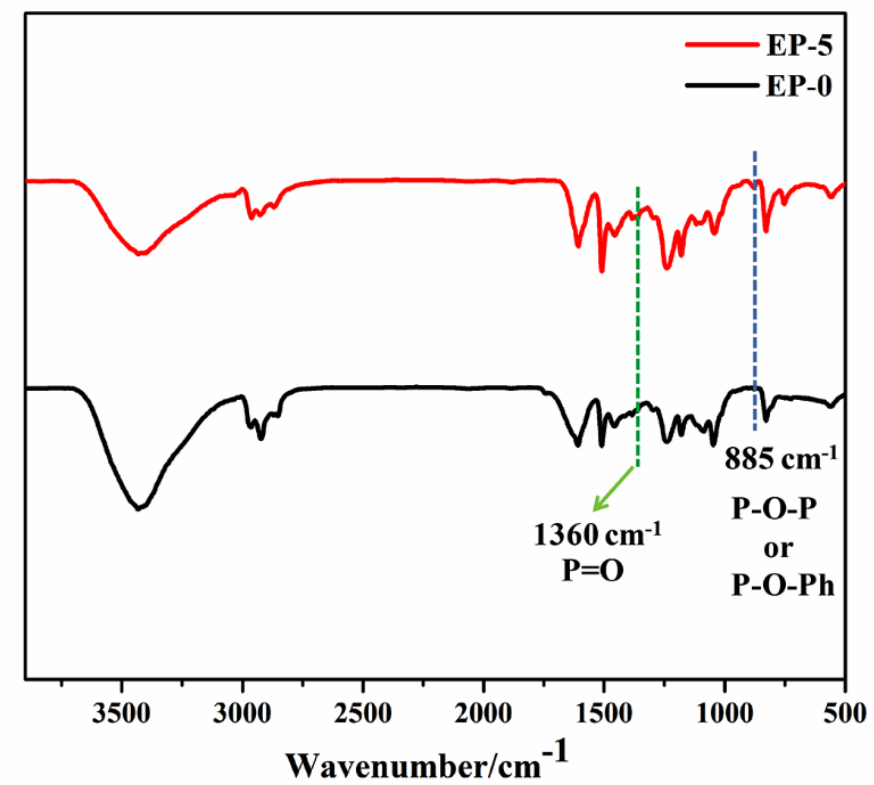

Fig. 13. FTIR spectra of the char residues of EP-0 and EP-5 composites after UL-94 tests

The morphology of the char residues after UL-94 tests was investigated by SEM. Fig. 14(a, b, c, and d) display the morphologies of char residues from EP-0, EP-3, EP-5 and EP-6, respectively. The residue of the EP-0 shows a loose and fluffy structure. This type of carbon layer is not conducive to prevent the transmission of combustible gases and heat. The introduction of PFDCHQ in EP matrix leads to more char residues, especially for EP-5, which effectively protects the internal epoxy resin matrix when the fire contacts them. But, an important phenomenon must be emphasized: all the char residues of EP composites are not continuous and compact, which may be helpful to the abrupt release of volatile gas, generating blowing-out effect to kill flame.

Based on the analysis above, we can attempt to explain the incoherence between LOI and UL-94 and CONE tests; namely, why the pHRR value decrease slightly in contrast to the excellent LOI and UL-94 performance for EP-5. Firstly, the $\mathrm{PO}$ and $\mathrm{PO}_{2}$ free radicals will come into play in the early stage after ignition to inhibit the fast combustion of EP matrix, which should facilitate the formation of char layer, as can be seen in UL-94 test (Fig. 14). Secondly, a suitable compact char layer produced in UL-94 test is definitely crucial to match initial blowing-out effect for killing flame rapidly (EP-5). Less or rich char layer is not conducive to generate blowing-out effect, indicating that a proper loading of PFDCHQ is necessary and critical. However, under the continuous irradiation in the CONE test, in spite of existing radical trapping effect in gas phase, the ferrocene mainly play an catalyzing degradation role on EP matrix, resulting in no sufficient char layer to prevent further combustion of EP matrix, then a high pHRR value appears for EP-5. Actually, more investigations are needed to elucidate profoundly the fire retardancy mechanism 
of EP/PFDCHQ system in the future.
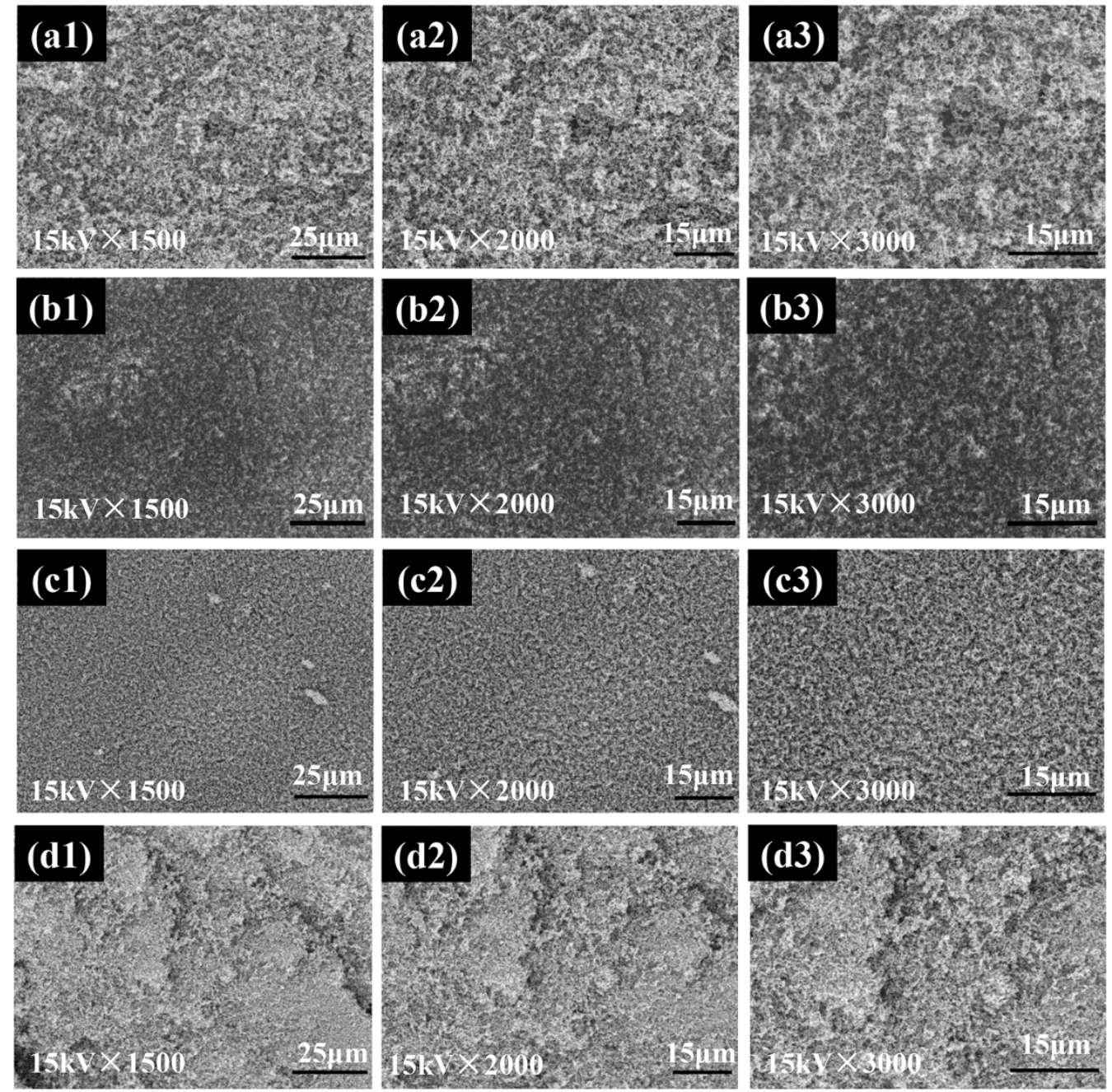

Fig. 14. Different magnifications of SEM micrographs of EP-0 (a1-a3), EP-3 (b1-b3), EP-5 (c1-c3) and EP-6 (d1-d3) after UL-94 tests

\subsection{Mechanical properties}

Mechanical property is the important factor to value the practical usability of composites. Impact strength, tensile strength, elongation at break and Young's modulus values of various EP/PFDCHQ composites are shown in Fig. 15 and Table S2. With the increasing PFDCHQ amount, the impact strength of EP/PFDCHQ composites tends to increase firstly and then decrease, and the Young's modulus is always higher than EP-0. The results could be explained by the introduction of rigid groups (ferrocene and benzene ring) into EP matrix. Compared to EP-0, the tensile strength and elongation at break of EP/PFDCHQ composites are both decreased a lot caused by the formation of internal stress during curing of EP [68]. The internal stress could create micro-cracks and voids to reduce the mechanical properties of materials. On the other hand, the excessive PFDCHQ is not uniformly distributed in the EP matrix, which causes the PFDCHQ acts as stress concentrators and decreases the mechanical properties of EP.

The SEM micrographs of EP-5 and EP-7 composites are shown in Fig.16. The fractured surface of EP-5 is smooth, while the cross-sectional morphology of EP-7 has many textures and is much 
rougher compared to EP-5, attributing to the agglomeration of excess PFDCHQ in epoxy resin matrix, thereby the agminated PFDCHQ may act as the stress concentration point to reduce the mechanical properties of EP/PFDCHQ composites.
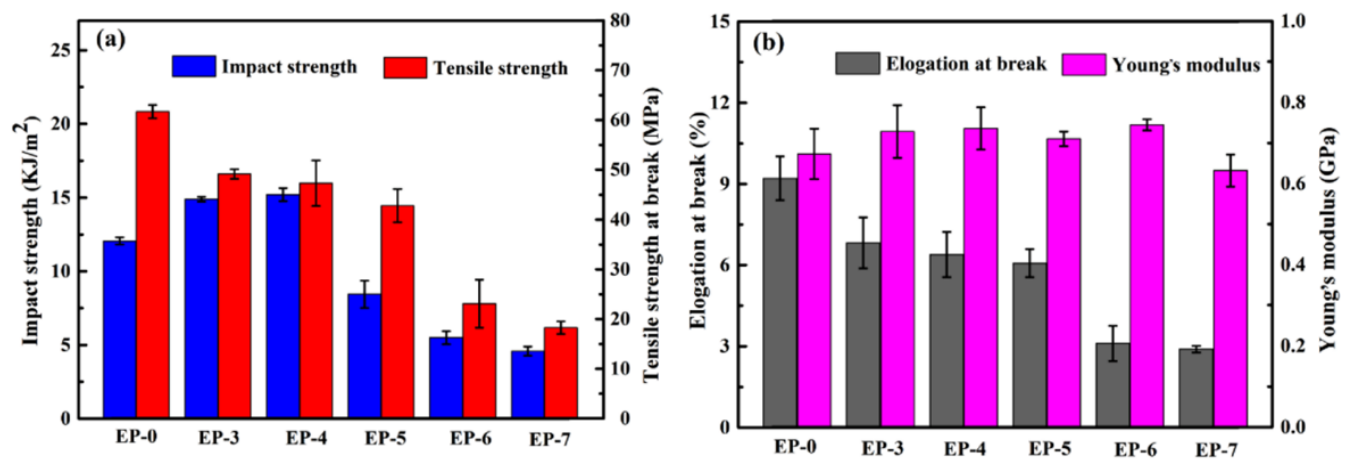

Fig. 15. The impact strength, tensile strength, elongation at break and Young's modulus of pure EP and EP/PFDCHQ composites
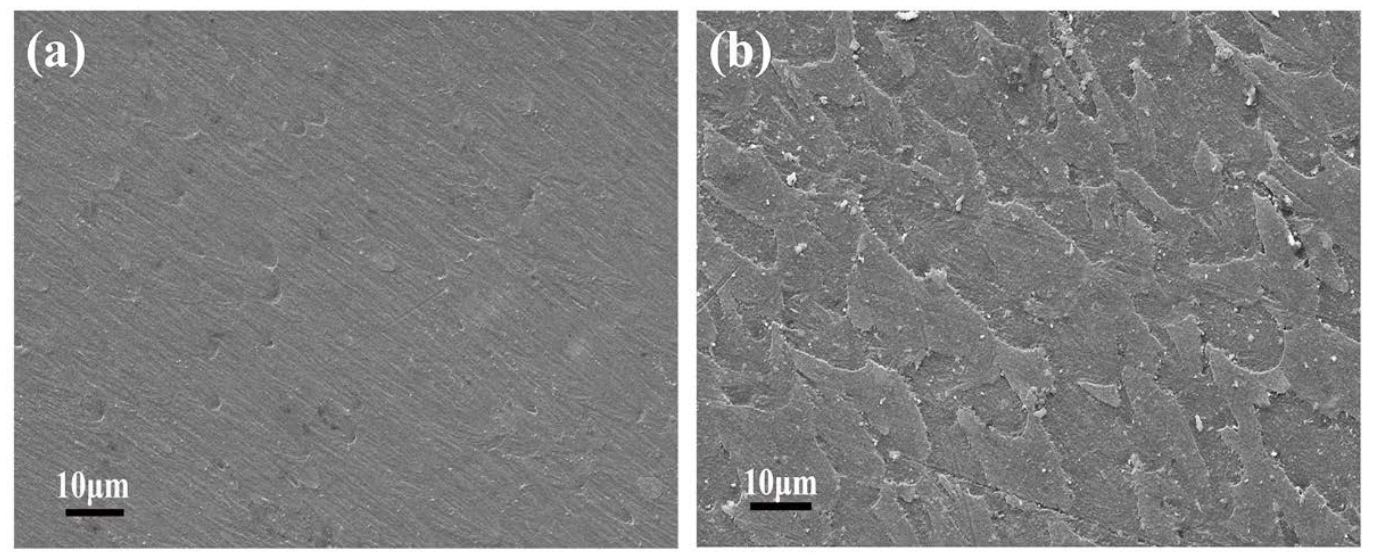

Fig. 16. SEM micrographs of the fractured surface of EP-5 (a) and EP-7 (b) composites

\section{Conclusion}

In this article, a novel DOPO and ferrocene-based oligomer (PFDCHQ) was first successfully synthesized and used as flame retardant in epoxy resin. The TGA results show that the PFDCHQ can contribute improved thermal and thermo-oxidative stability at high temperature region as well as char yield to epoxy resin matrix. The flame retardance and combustion behavior of EP-O and EP-5 were comprehensively investigated. With $5 \mathrm{wt} \%$ addition of PFDCHQ, the LOI value of EP- 5 is increased to $32.0 \%$ and can pass the $V-0$ rating. But it is unfortunate that the data of cone calorimeter test is not very well. The PFDCHQ can catalyze epoxy resin to form highly graphitization aromatic char in condensed phase and improve the char residue; PFDCHQ produces $\mathrm{PO}$ and $\mathrm{PO}_{2}$ fragments in gaseous phase for inhibiting flame development; moreover, an obvious blowing-out effect can be observed in UL-94 test for EP-3 and EP-5. This research provides a new idea for the molecular design of phosphorus and ferrocene-containing flame retardant system. 


\section{Acknowledgement}

This work was financially supported by the National Natural Science Foundation of China (51673160; 51373140), the China Scholarship Council (201508515104), the Postgraduate Innovation Fund Project by Southwest University of Science and Technology (17ycx015) and Longshan Academic Talent Research Support Plan of Southwest University of Science and Technology (17LZX404; 18LZX440)

\section{References}

[1] X. Zhang, Q. He , H. Gu, H.A. Colorado, S. Wei, Z. Guo, Flame-retardant electrical conductive nanopolymers based on bisphenol $\mathrm{F}$ epoxy resin reinforced with nano polyanilines, ACS Appl. Mater. Interfaces. 5 (2013) 898-910.

[2] Yeh J-M, Huang H-Y, Chen C-L, Su W-F, Yu Y-H. Siloxane-modified epoxy resin-clay nanocomposite coatings with advanced anticorrosive properties prepared by a solution dispersion approach. Surface and Coatings Technology. 2006;200:2753-2763.

[3] F. Lapoque, K. Redford, Curing effects on viscosity and mechanical properties of a commercial epoxy resin adhesive, Int. J. Adhes. Adhes. 22 (2002) 337-346.

[4] L. Chen, S.G. Chai, K. Liu, N.Y. Ning, J. Gao, Q.F. Liu, F. Chen, Q. Fu, Enhanced epoxy/silica composites mechanical properties by introducing graphene oxide to the interface, ACS Appl. Mater. Inter. 4 (2012) 4398-4404.

[5] X.M. Zhao, H.V. Babu, J. Llorca, D.Y. Wang, Impact of halogen-free flame retardant with varied phosphorus's chemical surrounding on the properties of diglycidyl ether of bisphenol-A type epoxy resin: synthesis, fire behaviour, flame-retardant mechanism and mechanical properties, RSC Adv. 6 (2016) 59226-59236.

[6] S.V. Levchik, E.D. Weil, Thermal decomposition, combustion and flame-retardancy of epoxy resins-a review of the recent literature, Polym. Int. 53 (2004) 1901-1929.

[7] Y.Z. Wang, X.T. Chen, X.D. Tang, X.H. Du, A new approach for the simultaneous improvement of fire retardancy, tensile strength and melt dripping of poly(ethylene terephthalate), J. Mate. Chem. 13 (2003) 1248-1249.

[8] Y. Zhang, L. Chen, J.J. Zhao, H.B. Chen, M.X. He, Y.P. Ni, J.Q. Zhai, X.L. Wang, Y.Z. Wang, A phosphorus-containing PET ionomer: from ionic aggregates to flame retardance and restricted melt-dripping, Polym. Chem. 5(2014) 1982-1991.

[9] Z.B. Shao, C. Deng, Y. Tan, M.J. Chen, L. Chen, Y.Z. Wang, An efficient mono-component polymeric intumescent flame retardant for polypropylene: preparation and application, ACS Appl. Mater. Interfaces. 6 (2014) 7363-7370.

[10] C. Deng, H. Yin, R.M. Li, S.C. Huang, B. Schartel, Y.Z. Wang, Modes of action of a monocomponent intumescent flame retardant MAPP in polyethylene-octene elastomer, Polym. Degrad. Stab. 138 (2017) 142-150.

[11] S.F. Liao, C. Deng, S.C. Huang, J.Y. Cao, Y.Z. Wang, An efficient halogen-free flame retardant for polyethylene: piperazinemodified ammonium polyphosphates with different structures, Chin. J. Polym. Sci. 34 (2016) 1339-1353.

[12] Z.M. Bai, L. Song, Y. Hu, R.K.K. Yuen, Preparation, flame retardancy, and thermal degradation of unsaturated polyester resin modified with a novel phosphorus containing acrylate, Ind. Eng. Chem. Res. 52 (2013) 12855-12864. 
[13] B. Schartel, B. Perret, B. Dittrich, M. Ciesielski, J. Krämer, P. Müller, V. Altstädt, L. Zang, M. Döring, Flame retardancy of polymers: the role of specific reactions in the condensed phase, Macromol. Mater. Eng. 301 (2016) 9-35.

[14] W. Kim, D. Hoang, H. Vothi, C. Nguyen, T. Giang, H. An, J. KIm, Synthesis, flame retardancy, and thermal degradation behaviors of novel organo-phosphorus compounds derived from 9,10dihydro-9-oxa-10-phosphaphenanthrene-10-oxide (DOPO), Macromol. Res. 24 (2016) 66-73. [15] A. König, E. Kroke. Flame retardancy working mechanism of methyl-DOPO and MPPP in flexible polyurethane foam, Fire Mater. 36 (2012) 1-15.

[16] M.M. Velencoso, A. Batting, J.C. Markwart, B. Schartel, F.R. Wurm, Molecular firefightinghow modern phosphorus chemistry can help solve the flame retardancy task, Angew. Chem. Int. Ed. (2018). DOI: 10.1002/anie.201711735.

[17] S. Yang, J. Wang, S. Huo, L.F. Cheng, M. Wang, The synergistic effect of maleimide and phosphaphenanthrene groups on a reactive flame-retarded epoxy resin system, Polym. Degrad. Stab. 115 (2015) 63-69.

[18] P.J. Chao, Y.J. Li, X.Y. Gu, D.D. Han, X.Q. Jia, M.Q. Wang, T.G. Zhou, T. Wang, Novel phosphorus-nitrogen-silicon flame retardants and their application in cycloaliphatic epoxy systems, Polym. Chem. 6 (2015) 2977-2985.

[19] B. Perret, B. Schartel, K. Stöß, M. Ciesielski, J. Diederichs, M. Döring, J. Krämer, V. Altsädt, Novel DOPO-based flame retardants in high-performance carbon fibre epoxy composites for aviation, Eur. Polym. J. 47 (2011) 1081-1089.

[20] U. Braun, U. Knoll, B. Schartel, T. Hoffmann, D. Pospiech, J. Artner, M. Ciesielski, M. Döring, R. Perez-Graterol, J.K.W. Ssndler, V. Altstädt, Novel phosphorus-containing poly(ether sulfone)s and their blends with an epoxy resin: thermal decomposition and fire retardancy, Macromol. Chem. Phys. 207 (2006) 1501-1514.

[21] Wang, Y. Hu, L. Song, H.Y. Yang, W.Y. Xing, H.D. Lu, Synthesis and characterization of a DOPOsubstitued organophosphorus oligomer and its application in flame retardant epoxy resins, Prog. Org. Coat. 71 (2011) 72-82.

[22] X. Wang, Y. Hu, L. Song, W.Y. Xing, H.D. Lu, Preparation, mechanical properties, and thermal degradation of flame retarded epoxy resins with an organophosphorus oligomer, Polym. Bull. 67 (2011) 859-873.

[23] I.D. Carja, D. Serbezeanu, T. Vlad-Bubulac, C. Hamciuc, A. Coroaba, G. Lisa, C .G. López, M.F. Soriano, V.F. Pérez, M.D. Romero Sánchez, A straightforward, eco-friendly and cost-effective approach towards flame retardant epoxy resins, J. Mater. Chem. A. 2 (2014) 16230-16241.

[24] X. Wang, Y. Hu, L. Song, W.Y. Xing, H.D. Lu, P. Lv, G.X. Jie, Flame retardancy and thermal degradation mechanism of epoxy resin composites based on a DOPO substituted organophosphorus oligomer, Polymer. 51 (2010) 2435-2445.

[25] N.N. Tian, J. Gong, X. Wen, K. Yao, T. Tang, Synthesis and characterization of a novel organophosphorus oligomer and its application in improving flame retardancy of epoxy resin, RSC Adv. 4 (2014) 17607-17614.

[26] X. Wang, S. Zhou, W. Xing, B. Yu, X. Feng, L. Song, Y. Hu, Self-assembly of Ni-Fe layered double hydroxide/graphene hybrids for reducing fire hazard in epoxy composites, J. Mater. Chem. A. 1 (2013) 4383-4390.

[27] Y. Zhang, X.A. Li, Z.P. Fang, T.R. Hull, A. Kelarakis, A.A. Stec, Mechanism of enhancement of intumescent fire retardancy by metal acetates in polypropylene, Polym. Degrad. Stab. 136 (2017) 
139-145.

[28] T. Tang, X.C. Chen, X.Y. Meng, H. Chen, Y.P. Ding, Synthesis of multiwalled carbon nanotubes by catalytic combustion of polypropylene, Angew. Chem. Int. Ed. 44 (2005) 1517-1520.

[29] N. Najfi-Mohajeri, G.L. Nelson, R. Benrashid, Synthesis and properties of new ferrocenemodified urethane block copolymers, J. Appl. Polym. Sci. 76 (2000) 1847-1856.

[30] W.A. Amer, L. Wang, H.J. Yu, A.M. Amin, Y. Wang, Synthesis and properties of a ferrocenebased metallomesogenic polymer containing bis(4-hydroxyoctoxyphenyl)sulfone, J. Inorg. Organomet. Polym Mater. 22 (2012) 1229-1239.

[31] S. Senthil, P. Kannan, Ferrocene-based organophosphorus liquid-crystalline polymers: synthesis and characterization, J. Polym. Sci., Part A: Polym. Chem. 39 (2001) 2396-2403.

[32] M.A. Hussein, A.M. Asiri, Organometallic ferrocene and phosphorus containing polymers synthesis and characterization, Des. Monomers. Polym. 15 (2012) 207-251. [33] K. Kishore, P. Kannan, K. Iyanar, Synthesis, characterization, and fire retardancy of ferrocene containing polyphosphate esters, J. Polym. Sci., Part A: Polym. Chem. 29 (1991) 1039-1044.

[34] S. Mehdipour-Ataei, S. Babanzadeh, New types of heat-resistant, flame-retardant ferrocenebased polyamides with improved solubility, React. Funct. Polym. 67 (2007) 883-892.

[35] D.J. Liao, Q.K. Xu, R.W. McCabe, H.V. Babu, X.P. Hu, N. Pan, D.Y. Wang, T.R. Hull, Ferrocenebased nonphosphorus copolymer: synthesis, high-charring mechanism, and its application in fire retardant epoxy resin, Ind. Eng. Chem. Res. 56 (2017) 12630-41263.

[36] J.X. Tao, W.J. Xiao, Structural chemistry of organotin ferrocenecarboxylic esters I. Synthesis and spectroscopic studies on dialkyltin esters of ferrocenecarboxylic acid FcCOOH and 1,1'ferrocenedicarboxylic acid Fc(COOH) 2, J. Organomet. Chem. 526 (1996) 21-24.

[37] F.W. Knobloch, W.H. Rauscher, Condensation polymers of ferrocene derivatives, J. Polym. Sci., Part A: Polym. Chem. 54 (1961) 651-656.

[38] X.D. Qian, L. Song, S.H. Jiang, G. Tang, W.Y. Xing, B.B. Wang, Y. Hu, Novel flame retardants containing 9,10-dihydro-9-oxa-10-phosphaphenanthrene-10-oxide and unsaturated bonds: synthesis, characterization, and application in the flame retardancy of epoxy acrylates, Ind. Eng. Chem. Res. 52 (2013) 7307-7315.

[39] M.S. Khan, A. Nigar, M.A. Bashir, Z. Akhter, A new ferrocene - containing polyamide prepared from an improved synthesis of 1,1'-ferrocene dicarbonyl chloride and ferrocene-based diamine, Synth. Commun. 37 (2007) 473-482.

[40] Y.X. Qi, W.H. Wu, L.J. Han, H.Q. Qu, X. Han, A.Q. Wang, J.Z. Xu, Using TG-FTIR and XPS to understand thermal degradation and flame-retardant mechanism of flexible poly(vinyl chloride) filled with metallic ferrites, J. Therm. Anal. Calorim. 123 (2015) 1263-1271.

[41] H.M. Zhu, J.H. Yan, X.G. Jiang, Y.E. Lai, K.F. Cen, Study on pyrolysis of typical medical waste materials by using TG-FTIR analysis, J. Hazard. Mater. 153 (2008) 670-676.

[42] R.K. Jian, P. Wang, W.S. Duan, J.S. Wang, X.L. Zheng, J.B. Weng, Synthesis of a novel P/N/Scontaining flame retardant and its application in epoxy resin: thermal property, flame fetardance, and pyrolysis behavior, Ind. Eng. Chem. Res. 55 (2016) 11520-11527.

[43] W.J. Liang, B. Zhao, C.Y. Zhang, R.K. Jian, D.Y. Liu, Y.Q. Liu, Enhanced flame retardancy of DGEBA epoxy resin with a novel bisphenol-A bridged cyclotriphosphazene, Polym. Degrad. Stab. 144 (2017) 292-303.

[44] Z.M. Bai, L. Song, Y. Hu, X. Gong, R.K.K. Yuen, Investigation on flame retardancy, combustion and pyrolysis behavior of flame retarded unsaturated polyester resin with a star-shaped 
phosphorus-containing compound, J. Anal. Appl. Pyrolysis. 105 (2014) 317-326.

[45] Y. Qiu, L.J. Qian, W. Xi, Flame-retardant effect of a novel phosphaphenanthrene/triazinetrione bi-group compound on an epoxy thermoset and its pyrolysis behaviour, RSC Adv. 6 (2016) 56018-56027.

[46] W.J. Huang, W.T. He, L.J. Long, W. Yan, M. He, S.H. Qin, J. Hu, Highly efficient flame-retardant glass-fiber-reinforced polyamide $6 \mathrm{~T}$ system based on a novel DOPO-based derivative: Flame retardancy, thermal decomposition, and pyrolysis behavior, Polym. Degrad. Stab. 148 (2018) 2641.

[47] C. Ma, B. Yu, N.N. Hong, Y. Pan, W.Z. Hu, Y. Hu, Facile synthesis of a highly efficient, halogenfree, and intumescent flame retardant for epoxy resins: thermal properties, combustion behaviors, and flame-retardant mechanisms, Ind. Eng. Chem. Res. 55 (2016) 10868-10879.

[48] J.L. Wang, C. Ma, P.L. Wang, S.L. W. Cai, Y. Hu, Ultra-low phosphorus loading to achieve the superior flame retardancy of epoxy resin, Polym. Degrad. Stab. 149 (2018) 119-128.

[49] H. Ebadi-Dehaghani, S. Mehdipour-Ataei, Novel ferrocene-based organometallic poly(ether sulfone amide imide)s: preparation, characterization, and properties, J. Inorg. Organomet. Polym. 22(2011) 223-234.

[50] C.L. Dong, A. Wirasaputra, Q.Q. Luo, S.M. Liu, Y.C. Yuan, J.Q. Zhao, Y. Fu, Intrinsic flameretardant and thermally stable epoxy endowed by a highly efficient, multifunctional curing agent, Materials. 9(2016) 1008-1023.

[51] P. Wang, Z.S. Cai, Highly efficient flame-retardant epoxy resin with a novel DOPO-based triazole compound: thermal stability, flame retardancy and mechanism, Polym. Degrad. Stab. 137(2017) 138-150.

[52] W.C. Zhang, X.D. He, T.L. Song, Q.J. Jiao, R.J. Yang, Comparison of intumescence mechanism and blowing-out effect in flame-retarded epoxy resins, Polym. Degrad. Stab. 112(2015) 43-51.

[53] B. Schartel, T.R. Hull, Development of fire-retarded materials-Interpretation of cone calorimeter data, Fire Mater. 31 (2007) 327-354.

[54] X.D. Qian, L. Song, B. Yu, B.B. Wang, B.H. Yuan, Y.Q. Shi, Y. Hu. K.K.Y. Richard, Novel organicinorganic flame retardants containing exfoliated graphene: preparation and their performance on the flame retardancy of epoxy resins, J. Mater. Chem. A. 1 (2013) 6822-6830.

[55] S. Brehme, B. Schartel, J. Goebbels, O. Fischer, D. Pospiech, Y. Bykov, M. Döring, Phosphorus polyester versus aluminium phosphinate in poly(butylene terephthalate) (PBT): Flame retardancy performance and mechanisms, Polym. Degrad. Stab. 96 (2011) 875-884.

[56] N.H. Huang, J.Q. Wang, A TGA-FTIR study on the effect of $\mathrm{CaCO}_{3}$ on the thermal degradation of EBA copolymer, J. Anal. Appl. Pyrolysis. 84 (2009) 124-130.

[57] Y.Y. Dong, Z. Gui, Y. Hu, Y. Wu, S.H. Jiang, The influence of titanate nanotube on the improved thermal properties and the smoke suppression in poly(methyl methacrylate), J. Hazard. Mater. 209 (2012) 34-39.

[58] T. Mariappan, C.A. Wilkie, Flame retardant epoxy resin for electrical and electronic applications, Fire Mater. 38 (2014) 588-598.

[59] D. Wang, L. Song, K.Q. Zhou, X.J. Yu, Y. Hu, J. Wang, Anomalous nano-barrier effects of ultrathin molybdenum disulfide nanosheets for improving the flame retardance of polymer nanocomposites, J. Mater. Chem. A. 3 (2015) 14307-14317.

[60] X. Wang, S. Zhou, W.W Guo, P.L. Wang, W.Y. Xing, L. Song, Y. Hu, Renewable Cardanol-Based Phosphate as a Flame Retardant Toughening Agent for Epoxy Resins. 
ACS Sustain. Chem. Eng. 5 (2017) 3409-3416.

[61] A.H. Yang, C. Deng, H. Chen, Y.X. Wei, Y.Z. Wang. A novel Schiff-base polyphosphate ester: Highly-efficient flame retardant for polyurethane elastomer, Polym. Degrad. Stab. 144 (2017) 7082.

[62] Y. Zhang, B. Yu, B.B. Wang, K.M. Liew, L. Song, C.M. Wang, Y. Hu, Highly effective P-P synergy of a novel DOPO-based flame retardant for epoxy resin, Ind. Eng. Chem. Res. 56 (2017) 12451255.

[63] S. Zhou, L. Song, Z.Z. Wang, Y. Hu, W.Y. Xing, Flame retardation and char formation mechanism of intumescent flame retarded polypropylene composites containing melamine phosphate and pentaerythritol phosphate, Polym. Degrad. Stab. 93 (2008) 1799-1806.

[64] L. Zhang, Y.H. Wang, Q. Liu, X.F. Cai, Synergistic effects between silicon-containing flame retardant and DOPO on flame retardancy of epoxy resins, J. Therm. Anal. Calorim. 123 (2015) 1343-1350.

[65] M. Bugajny, S. Bourbigot, M.L. Bras, R. Delobel, The origin and nature of flame retardance in ethylene-vinyl acetate copolymers containing hostaflam AP 750, Polym. Int. 48 (1999) 264-270. [66] Z.Z. Wang, P. Lv, Y. Hu, K.L. Hu, Thermal degradation study of intumescent flame retardants by TG and FTIR: Melamine phosphate and its mixture with pentaerythritol, J. Anal. Appl.

Pyrolysis. 86 (2009) 207-214.

[67] G.H. Hsiue, S.J. Shiao, H.F. Wei, W.J. Kuo, Y.A. Sha, Novel phosphorus-containing dicyclopentadiene-modified phenolic resins for flame-retardancy applications, J. Appl. Polym. Sci. 79 (2001) 342-349.

[68] S. Gaan, S.Y. Liang, H. Mispreuve, H. Perler, R. Naescher, M. Neisius, Flame retardant flexible polyurethane foams from novel DOPO-phosphonamidate additives, Polym. Degrad. Stab. 113 (2015) 180-188. 